\title{
SHAPING THE COVID DECADE Addressing the long-term societal impacts of COVID-19
}

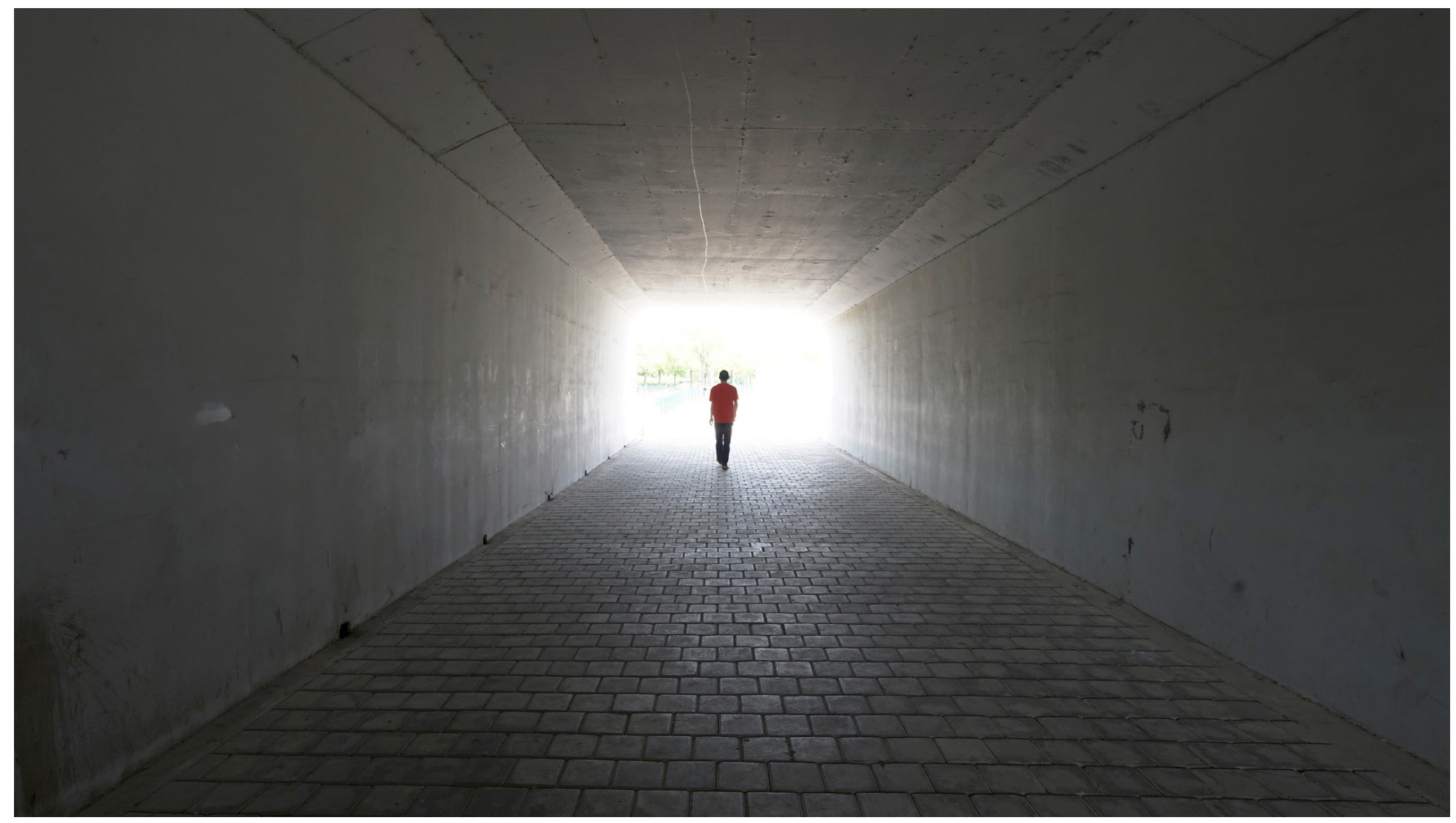

31 The British Academy

31 COVID-19 and Society 


\section{Contents}

Foreword

Executive summary

1.0 Introduction

1.1 Where we began 11

1.2 Shaping the COVID decade 12

\subsection{Evidence and Analysis}

2.1 Nine areas of long-term societal impact 14

$\begin{array}{lll}2.2 & \text { Dealing with uncertainty } & 17\end{array}$

$\begin{array}{lll}2.3 & \text { Place, scale, and time } & 18\end{array}$

\subsection{Policy}

3.1 Build multi-level governance structures based on empowering participation, engagement and cooperation to strengthen the capacity to identify and respond to local needs

3.2 Improve the way we develop, share and communicate knowledge, 23 data and information to enable all decision-makers to work from shared understanding of the facts

3.3 Prioritise investment in digital infrastructure as a critical service to eliminate the digital divide, improve communication and joint problem solving, and create a more equitable basis for education and employment

3.4 Reimagine urban spaces to support sustainable and adaptable local businesses, amenities, and lifestyles

3.5 Create a more agile, responsive education and training system capable of meeting the needs of a new social and economic environment and acting as a catalyst to develop and enhance our future

3.6 Strengthen and expand community-led social infrastructure that underpins the vital services and support structures needed to enhance local resilience, particularly in the most deprived areas 
3.7 Empower a range of actors, including business and civil society, to work together with a sense of social purpose to help drive a solid strategy for recovery across the economy and society

4.0 The policy environment in $\mathbf{2 0 3 0}$

4.1 CLEAR principles of the policy environment 


\section{Foreword}

\section{A vital role for the humanities and social sciences in policymaking in the COVID decade}

No single metaphor can capture the complexity or ramifications of the societal impact of COVID-19. Its arrival, ever-changing twists and turns, dilemmas it presents, and devastating impacts have demanded practical and policy decisions at a phenomenal pace. It has confronted us with icebergs lurking beneath their tips and what we thought were fields that turned out to be deserts, but more fundamentally we see the urgent need to connect and integrate our responses - to join up policy and implementation across the whole set of societal elements.

Even if there are precedents in the history of pandemics, wars, and other seismic events, there has never been a time when we had more evidence of what is occurring, or have been able to analyse and respond to it with such speed and comprehensiveness. There are diverging impacts on people's lives, the economy, our culture, and our expectations for the future, as well as profound impacts on, and of levels of, inequality. These point to new sets of priorities, new connections between disparate policy areas, and new policy challenges. 'The science' does not exist as a thing or fact. Rather, science, in broad terms, is a continual process of discovery and learning in which we must embrace increasing complexity to make more progress. It is evident that the societal impact of the pandemic cannot be mitigated by medicine, science, and technological innovation alone and requires the combined weight of the social, cultural, political, economic, and historical perspectives that the humanities and social sciences offer.

I am pleased to present the British Academy's review of the policy implications of COVID-19. In September 2020, Sir Patrick Vallance posed a question to the British Academy - 'What are the long-term societal impacts of COVID-19?' This was, and remains, possibly the most important question facing the country. Despite some trepidation at the outset, we welcomed this challenge and initiated two reviews to underpin our response. One is our substantive review of evidence of the impacts of COVID-19, The COVID decade, and the second is this companion report which reviews the policy implications.

What follows is intended both to be of immediate value for policymakers and to serve as a significant staging post in the Academy's journey on its efforts to inform and enrich debate around society's greatest challenges, underpinned by evidence and insight from across the humanities and social sciences. Using an extensive evidence base we set out seven strategic goals for policymakers and a framework for future policy development.

This review builds on the Academy's work earlier in 2020 on Shape the Future, which held a series of 20 workshops to begin developing a more comprehensive perspective on policy, framed through expertise in humanities and social sciences. With that work, and having established nine major areas of societal impact of COVID-19 in our extensive evidence review, we wanted to ensure that our conclusions on policy would be robust and reflect a strong consensus. The present review therefore involved a wide-ranging, intensive, and repeated process of consultation with academic experts, research bodies, senior policy specialists, and experts from many sectors. 
Together, the evidence and policy reports represent the most substantial review ever undertaken by the British Academy. We must recognise the astonishing generosity of so many of our own Fellows and researchers, of our external advisory reference group, our internal steering group, and the very many research teams that have been so willing to provide written and oral evidence, comment on documents, and join multiple lengthy meetings. The direct contributors to this work number in their hundreds and many more contributed indirectly. As the Academic Lead for both the evidence and policy reviews, it has been my great privilege to work so intensively and closely with the Academy's outstanding policy team, and to be so well supported by the President, our Chief Executive, and our Vice-President (Public Policy).

We believe that this report lays out key priorities for policy now and in the decade ahead. Addressing the impact of COVID-19 on society will require energetic collaboration across the public and private sectors, industry, voluntary and civil organisations, and across sectors of society that are often in opposition over particular issues or values. We intend that the present work should be the basis for a strong and effective policy environment that fully embraces what humanities and social sciences have to offer society.

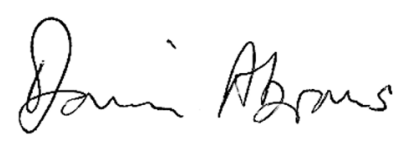

Professor Dominic Abrams FBA

Lead Fellow, British Academy COVID-19 and Society programme 


\section{Executive summary}

In September 2020, the British Academy was asked by the Government Office for Science to produce an independent review to address the question: What are the long-term societal impacts of COVID-19? This short but substantial question led us to a rapid integration of evidence and an extensive consultation process. As history has shown us, the effects of a pandemic are as much social, cultural and economic as they are about medicine and health. Our aim has been to deliver an integrated view across these areas to start understanding the long-term impacts and how we address them.

Our evidence review - in our companion report, The COVID decade - concluded that there are nine interconnected areas of long-term societal impact arising from the pandemic which could play out over the coming COVID decade, ranging from the rising importance of local communities, to exacerbated inequalities and a renewed awareness of education and skills in an uncertain economic climate.

From those areas of impact we identified a range of policy issues for consideration by actors across society, about how to respond to these social, economic and cultural challenges beyond the immediate short-term crisis. The challenges are interconnected and require a systemic approach - one that also takes account of dimensions such as place (physical and social context, locality), scale (individual, community, regional, national) and time (past, present, future; short, medium and longer term).

History indicates that times of upheaval - such as the pandemic - can be opportunities to reshape society, but that this requires vision and for key decisionmakers to work together. We find that in many places there is a need to start afresh, with a more systemic view, and where we should freely consider whether we might organise life differently in the future.

In order to consider how to look to the future and shape the COVID decade, we suggest seven strategic goals for policymakers to pursue: build multi-level governance; improve knowledge, data and information linkage and sharing; prioritise digital infrastructure; reimagine urban spaces; create an agile education and training system; strengthen community-led social infrastructure; and promote a shared social purpose. These strategic goals are based on our evidence review and our analysis of the nine areas of long-term societal impact identified. We provide a range of illustrative policy opportunities for consideration in each of these areas in the report that follows. 


\section{Seven policy goals to shape a COVID decade}

\section{Build multi-level governance structures based on empowering participation, engagement and cooperation to strengthen the capacity to identify and respond to local needs.}

Whether focussing on the recovery or improving our responsiveness and resilience to future crises, policies and decisions must be made and implemented at different levels of governance - and for them to work most effectively, these levels must operate in strong partnership, with both vertical and lateral collaboration.

The tensions between localised and centralised governance are longstanding. But the current crisis has highlighted both a clear justification and a unique and powerful opportunity for a thorough, transparent and bipartisan assessment and reform of the role and powers of central and local government - and, crucially, how they interact across a range of policy issues and areas of service provision.

\section{Improve the way we develop, share and communicate knowledge, data and information to enable all decision-makers to work from shared understanding of the facts.}

The quality and consistency of the flows of information within government, between different departments and agencies and between government and non-state actors including the wider public - should be improved in order to mitigate more effectively the social impacts of this crisis and be better prepared for future crises. Decisionmakers need to make data sharing with other agencies the default position, including at international levels when appropriate, as a coordinated and shared view of the facts is in the public interest.

Efforts should be taken to make communication a two-way process, informing while also engaging people and organisations to participate by feeding back information, with greater transparency of sources to improve trust. Communication needs to reflect and learn from people's lived experience.

\section{Prioritise investment in digital infrastructure as a critical public service to eliminate the digital divide, improve communication and joint problem solving, and create a more equitable basis for education and employment.}

Successful recovery demands that the country prioritises and accelerates its investment in digital infrastructure. The lockdown has created an opportunity to embrace digital technology in enhancing the way we do things, but it has also highlighted the disparities in digital access and heightened the need to ensure no groups are left behind by the rapid changes in the way people live, work and learn.

The existing geographical and socioeconomic inequalities in digital access across the country should be tackled as they remain a primary barrier to levelling up. The issue is so fundamental that government and other actors could treat investment in digital infrastructure as a critical, life-changing public service, taken forward with the same zeal that we saw in 19th-century Britain with the railway boom or, in the 20th century, the construction of the national grid. 


\section{Reimagine urban spaces to support sustainable and adaptable local businesses, amenities and lifestyles.}

The effects of the pandemic provide a crucial thrust to rethink the relationship between urban, rural and other environments with a more efficient and sustainable future in mind. Central and local governments must come to a consensus around a comprehensive but place-sensitive land use plan that creates a viable blueprint for the development of flexible, sustainable neighbourhoods, towns and cities.

The regeneration of towns and cities will need a range of skills, offering new educational and employment opportunities, helping to transition the economy to sustainable growth. It will also protect society and the environment against unsustainable urban-to-rural migration and suburban sprawl, which would have environmental, cultural and social consequences and could make the country's commitments to achieving net zero all the more difficult.

\section{Create a more agile, responsive education and training system capable of meeting the needs of a new social and economic environment and acting as a catalyst to develop and enhance our future.}

COVID-19 will have lasting implications for our economy, labour market and communities, which will not be distributed equally but could exacerbate existing employment trends across sectors and geographic communities and disproportionately impact the vulnerable. These changes will require a rethinking of the types of knowledge and skills needed in a new social and economic environment, with an emphasis on using education and training as a catalyst to develop and enhance our future while making us better prepared for the challenges we could face.

Current cohorts in education have also suffered a loss of learning opportunities unprecedented in modern times, which has also increased existing educational inequalities. And while educational strategy is driven by a systems-level approach, policymakers in central government should take account of the different contexts of schooling locally and allow enough flexibility for local actors to review and respond in the most appropriate way, on the basis of local knowledge and experience, in partnership with central government and national agencies. Now that the education system has been rapidly equipped to deliver many forms of education remotely, there is an opportunity to be seized to distribute the opportunity to learn more widely and for longer, in future, both in terms of both the range of provision and its demographic reach.

\section{Strengthen and expand community-led social infrastructure that underpins the vital services and support structures needed to enhance local resilience, particularly in the most deprived areas.}

Community-led social infrastructure has been an essential but precarious lifeline in the crisis, and its importance will only grow as we look to respond to and mitigate the long-term societal effects. These infrastructures must be further supported and enhanced if we are to rely on them in the future.

We must also look closely at the critical role of communities in rebuilding trust and cohesion after the crisis, ensuring the right infrastructure is in place to strengthen trust both within and between different groups and communities, which in turn builds social capital and underpins wider recovery demands for greater economic productivity and resilience. Important civic institutions like universities, colleges, places of worship, museums and sports clubs all need to act as supportive nodes in the underlying structures which support and empower communities. 


\section{Empower a range of actors, including business and civil society, to work together with a sense of social purpose to help drive a solid strategy for recovery across the economy and society.}

The significant achievements in social, scientific, technological and cultural innovation during the crisis were not driven by market competition or state direction alone: different actors worked together towards a common goal because of a shared sense of urgency and necessity. If we are truly to work towards a positive future, we must strive to enhance this collective sense of social purpose and not revert to atomised, adversarial interests.

The pandemic brought out some of the best features of a compassionate, cooperative and innovative society, driven by the shared purpose of responding to the crisis. However, we need to turn these pockets of purpose-driven cooperation during a crisis into a solid strategy for recovery across the economy and society. Government, business, the media and civil society can come together to actively support and encourage individuals to contribute their energies, break down divides and create a sense of national unity and duty akin to that seen in the war effort.

\section{Building a more resilient framework for policy in $\mathbf{2 0 3 0}$}

The pandemic has also revealed limitations in our policy framework and there is much to learn about how to improve policymaking to ensure government can manage future crises - be that another pandemic or something entirely different. In addition to the seven strategic policy goals, we conclude that a more resilient and effective state should follow five principles which we label CLEAR: Communicative, Learning, Engaging, Adaptive and Relational. These principles can work collectively to support the delivery of the strategic policy goals and be used as a framework for a successful recovery by 2030 .

\section{Conclusion}

COVID-19 has generated a series of social, economic and cultural effects that will have long-term impacts: we are in a COVID decade and, indeed, many of these effects will be felt far beyond that. In particular, the pandemic has exposed, exacerbated and solidified existing inequalities in society. However, it is not just a case of the pandemic making existing problems worse. It has also exposed areas of strength, resilience, creativity and innovation.

We argue that policymakers need to act systemically across areas to respond to the emerging trends and that there are a wide range of policy opportunities open to them. Following our substantial evidence review and extensive and repeated consultations with a wide array of leading experts across SHAPE ${ }^{1}$ disciplines, as well as government and civil society, we also put forward CLEAR principles which provide a framework for governments to create effective policy, especially in a crisis.

During the immediate COVID-19 crisis government necessarily had to rely increasingly on input from external experts and made rapid adaptations to enable the collection and sharing of data and evidence. It is important that this continues even as we move away from the immediate crisis to dealing with longer-term issues. It 
will continue to be vital to bring in different kinds of expertise, especially that found within the humanities and social sciences, as we turn from the medical crisis to dealing with the social, economic and cultural impacts emerging from the pandemic.

In this review, the British Academy has undertaken the substantial task of beginning to answer the longer-term question about what the societal impacts of COVID-19 will be and how we address them. What follows can be boiled down to an interrelated set of 9 areas of long-term impact, 7 strategic policy goals and 5 key principles of a facilitative policy environment for 2030. Behind those numbers lies a wealth of detailed evidence, thoroughly tested reasoning and substantial intellectual and professional consensus. The situation continues to evolve, and new evidence will help us build a richer picture of the pandemic's effects. We aim here to provide decision-makers with a sense of how to start to respond to these longer-term impacts on the basis of the current evidence, and how to shape the COVID decade. We will look forward to opportunities to develop this programme in partnership with policymakers, civil society, business and actors at all levels of society. 


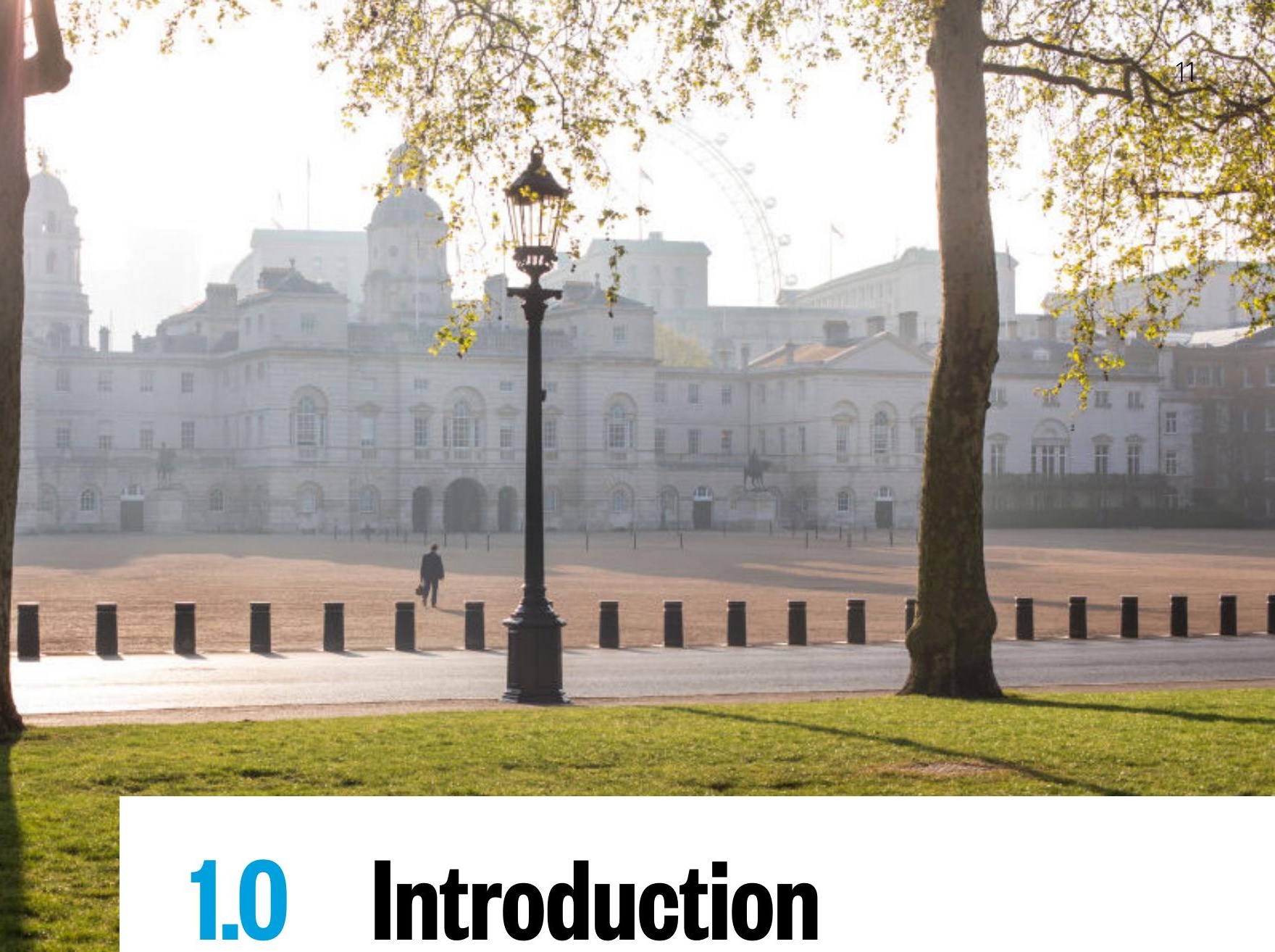

1.1

Where we began

The British Academy was asked by the Government Office for Science in September 2020 to produce an independent review of existing evidence to address the question: What are the long-term societal impacts of COVID-19? This short but substantial question led us to a rapid integration of the evidence and an extensive consultation process. Ultimately, we have not only assessed the long-term impacts of COVID-19, but also answered two further critical questions: What are the challenges and opportunities that COVID-19 has unearthed in different policy areas? And what does this tell us about the policy framework and wider policy landscape that might underpin progress towards shaping a positive post-pandemic future?

In the six months prior to this review, the Academy had engaged in a wide-ranging consultation involving a large number of leading scholars and practitioners across the humanities and social sciences. ${ }^{2}$ That initiative culminated in a detailed publication summarising over 20 workshops which brought together the insights from the social sciences, humanities and the arts to understand how we can shape a positive post-pandemic future. ${ }^{3}$ One of the most powerful ideas emerging from this effort was that pandemics are as much social and economic events as health and medical ones. The impacts go well beyond health and medical, changing lives and livelihoods, communities and economies, within and across nations.

The current review addresses these ideas and questions but examines them more specifically through the lens of our experience of the pandemic. We consulted across the $\mathrm{SHAPE}^{4}$ research community, engaging not only our fellowship and early career researcher community, but also a range of external stakeholders. We put out a wide-

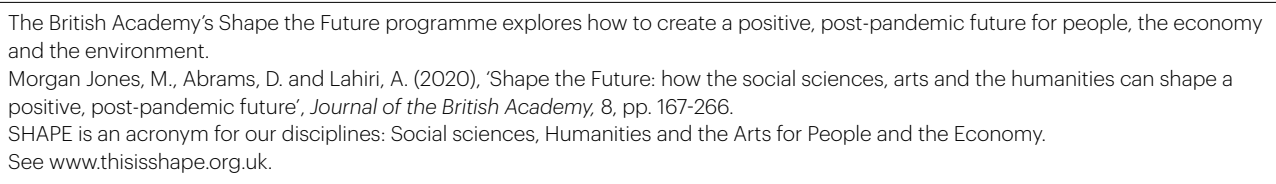


ranging call for evidence to which over 60 organisations and individuals across our community responded. We rapidly scanned and reviewed hundreds of pieces of existing research and policy analysis, published or underway, as well as available 'grey literature' from a variety of sources. We received a series of 12 detailed evidence syntheses on specific areas identified through our scoping work. We integrated all this evidence through six workshops and roundtables involving over 40 individuals. We continually tested, elaborated and refined the insights through consultation and discussion with our expert advisors from academia, the civil service, the voluntary sector and practitioner sources.

Our review has resulted in two reports. The accompanying report, The COVID decade: understanding the long-term societal impacts of COVID-19, presents the evidence and summarises our assessment of the nine areas of long-term impact of COVID-19. These are not exhaustive, but they all require significant attention. Importantly, our assessment stresses that these long-term impacts could, without significant intervention on the part of government, civil society, business or other stakeholders, induce serious harm to society or become crucial missed opportunities for recovery.

\subsection{Shaping the COVID decade}

This document is the policy-focused report. It considers how we might address those nine areas of societal impact in an interconnected manner to avoid the most negative impacts and accentuate the positive opportunities. To support policymakers in planning their interventions, it actively engages with the medium- to long-term uncertainties we face and points to policy goals that could help mitigate the risks and grasp the opportunities - no matter the future context we face. In considering the policy goals, our evidence suggests that they should create positive possibilities for governments of any political complexion and should encompass the local and hyperlocal as much as the national and supranational.

The evidence of long-term impact points strongly to factors that preceded and will outlast the pandemic. This is to be expected, as it is also the pattern that pandemics and major crises throughout history have exhibited. Regardless of whether the impacts involve modulations of prior trajectories or are unique products of this pandemic, the purpose of this policy report is to establish a better position to understand which societal impacts we may want to cement, which to reverse and the likely trade-offs among priorities and outcomes. It is in undertaking this analysis and understanding the nature of these trade-offs, their interactions and contingencies, and where we might learn from previous experience that evidence and interpretation provided by humanities and social science disciplines is essential.

One of the most powerfully emerging themes from all this review work, in both the assessment of the impact evidence and the analysis of policies to address the impacts, is the very idea that the challenges and opportunities are interconnected. The policy analysis in this report is predicated on the extensive and detailed analysis of the evidence base summarised in the accompanying report. In producing this analysis, it is very easy to identify specific areas that need urgent attention, but it is also vital to understand on the wider picture. The more immediately visible impacts must be balanced against the less visible, but no less severe, longer-term risks and opportunities.

A central conclusion is that policy must be developed to address the interconnections and interdependencies among the impacts. Addressing each impact in a piecemeal way will always fail to deliver as much as it could. For that reason, as we developed strategic policy avenues, we always asked whether these spanned different types of 
impact, pointed to a better integrated and more dependable basis for progress and would ultimately bring wider and more equitable benefits for all.

Although we have identified nine very important impacts, the policy avenues and framework are intended to address a wide range of other impacts. We do not, for example, list environmental sustainability or student's mental health, progression and career prospects as high-level impacts - but we believe that because the policy avenues and framework are intended to address the fact that so many impacts have interconnected, underlying causes and effects, they should help to address many other broad and specific challenges ahead.

Since our starting question is about the longer-term societal impacts of COVID-19, we also brought the issue of context to bear more directly on our thinking. The constant background in our discussions has therefore been consideration of the roles of time, scale and space - or, to put it more concretely, the timing and longevity of policy; the levels at which implementation occurs and the interconnections among them; and the places that are involved and the people within them.

This report, despite the depth and detail of the evidence, takes a deliberately highlevel perspective. We are facing a COVID decade - a decade that will be shaped by its origins, a decade that creates global challenges, and one that calls out for more ambitious and open-minded thinking about how to improve the future. The COVID decade, like previous turning points in our history, will be defined by how government, business, civil society and individuals respond to the scale, depth and complexity of the long-term effects of the disease and the repercussions of necessary short-term strategies such as national lockdown.

Unabated, the long-term impact of COVID-19 on our society could be severe, lasting much longer than a decade, and many of the chances we have for tackling existing societal problems could become more constrained or disappear. In this report, we look strategically at the options for policy intervention, bringing together the evidence on what the optimum policy focus should be in the face of longer-term uncertainties, and how different actors can work together to bring about positive outcomes, mitigating the most harmful impacts of COVID-19 on society while taking forward new opportunities for the UK to thrive.

What follows can be boiled down to nine areas of long-term societal impact, seven strategic policy goals and five principles of a facilitative policy environment for 2030 - but behind these numbers lies a wealth of detailed evidence, thoroughly tested reasoning and substantial intellectual and professional consensus. We aim to provide decision-makers with a sense of how to understand the longer-term societal impacts of COVID-19. Though the situation continues to evolve, new evidence will only help us build a richer picture of the pandemic's effects and how we might respond.

While there is a need for rapid adaptation and intervention in relation to the immediate effects of the ongoing crisis, it is also urgent to address the longerterm prospects, and the impacts that will occur from widening inequalities across multiple indicators, poor labour market outcomes and worsening mental and physical health effects. The immediately visible impacts need to be balanced with this multidimensional and longer view. Drawing on the best available evidence, our purpose is to identify a set of strategic goals for the policy response, designed to address the key areas of long-term impact. The benefit of this approach is that a range of policy options can be considered under each goal, providing flexibility and agility to decision-making while ensuring that decisions are grounded in the evidence. Our aim is that this thinking will provide a solid basis for policy, research and action in the years ahead. 


\section{Increased importance of local communities}

Local communities have become more important than ever during the pandemic. Local and hyper-local charitable and voluntary organisations have been crucial to the response to COVID-19, but there are inequalities between communities based on the strength of community infrastructures. National capacity to respond to changing circumstances and challenges requires effort to sustain strong communities and community engagement at local levels.

\section{Low and unstable levels of trust in governance}

Following a brief initial increase, trust in the UK Government and feelings of national unity are in decline. Trust in local government and feelings of local unity have been higher and steadier. Declining trust is a major challenge that needs to be addressed because it undermines the ability to mobilise public behaviour and support for wider social and health benefits.

\section{Widening geographic inequalities}

Geographic and spatial inequalities have widened. Health and wellbeing, local economic risk and resilience, poverty and deprivation and response planning all have an important place dimension that has shaped the impact of the crisis. Attending to these inequalities is important because they expose ways in which the combination of geographical location, physical infrastructure and social conditions implies that different priorities may be needed in different places.

\section{Exacerbated structural inequalities}

COVID-19 and the government response to it have impacted different people in different ways, often amplifying existing structural inequalities in income and poverty, socioeconomic inequalities in education and skills, and intergenerational inequalities - with particular effects on children (including vulnerable children), families with children and young people. There are differential effects within these along dimensions of gender, race and ethnicity and social deprivation which have been both exposed and exacerbated, as well as effects related to social development, relationships and mental health which are all variably affected and interlinked. The evidence highlights that addressing the underlying interconnected propellants of inequality is a key challenge ahead.

\section{Worsened health outcomes and growing health inequalities}

Like structural inequalities, health outcomes for COVID-19 have followed patterns of existing health inequalities. There are ongoing health impacts from 'long COVID' as well as from delays in care seeking and reprioritisation of resources. Deficiencies in home and community care infection prevention and control measures, and inequalities in the structure and funding of social care provision, have been laid bare. These are all areas that need significant attention to avoid critical gaps in the health system going forward. 


\section{Greater awareness of the importance of mental health}

The pandemic and various measures taken to address it have resulted in differential mental health outcomes. Access to support for new cases and for those with preexisting conditions has also been disrupted, in addition to services for children and young people. Both have the potential to result in long-term mental health impacts for particular groups if there is not a renewed focus on the causes of poor mental health and on solutions for sustaining mental health across society, including by tackling the structural and root causes of inequality.

\section{Pressure on revenue streams across the economy}

Although detailed economic analyses were outside the scope of the report, there are likely to be additional pressures on government spending in the medium to long term, as a result of increasing levels of debt and possible falling tax revenues due to risks around unemployment, failing businesses, decreased consumption and significant shifts in the structure of the economy. It will be increasingly important to address the balance of revenue generation and weigh up expenditure against non-economic impacts, considering a diversity of mechanisms and actors to meet societal goals.

\section{Rising unemployment and changing labour markets}

Employment and household income levels have fallen and will likely worsen for the foreseeable future. This will lead to an increased dependency on social security, which the current system may be ill equipped to deal with effectively. This will matter not only for those who are (or will become) dependent on state social security support, but also because it may require significant adjustments to the social security system in order for it to keep pace with demand.

\section{Renewed awareness of education and skills}

The consequences of lost access to education at all levels, coupled with changes to assessments, will be felt for years to come, and wholly recovering lost education is unfeasible. This has exacerbated existing socioeconomic inequalities in attainment and highlighted digital inequality. Because a high-skill economy will be essential for future prosperity and for society to thrive, it will be vital to consider whether lifelong educational opportunities are sufficiently comprehensive, diverse and flexible. 


\subsection{Dealing with uncertainty}

No matter the conditions, many of the choices for proceeding in the coming decade in the context of uncertainty will create not just political and economic but also legal, ethical and moral challenges. These will affect what is prioritised, how policy is implemented and the ramifications for culture and society. To grapple with these challenges effectively, we will need insight from stakeholders and disciplinary communities across science and medicine and the humanities and social sciences to assess the various paths forward.

Therefore, as the final stage of our analytical engagement with the evidence, we stretched our understanding of the potential longer-term impacts of COVID-19 and the policy response by testing the robustness of our evidence synthesis against the uncertainty and complexity of how the crisis might evolve. This led to our analysis and development of policy goals and opportunities.

To undertake this analysis, we created a set of scenarios that allowed us to consider a range of societal impacts and policy directions without knowing, or trying to predict concretely, how the COVID-19 crisis will evolve. These broad scenarios provided a flexible framework within which to examine different opportunities and challenges and the potential interventions that can be made over the decade. The scenarios consider the known facts about the COVID-19 pandemic and the response so far, to give a generalised picture of how people, public services, the economy and decisionmaking might be affected. Then, in a series of workshops during December 2020, a range of academic and policy experts were presented with a preliminary version of our impact evidence and asked to discuss it in relation to, and in light of, these scenarios. Insights from these workshops informed the final set of strategic policy goals for addressing the long-term impacts of COVID-19.

Our baseline scenario took what we know about the development of vaccines against COVID-19 and assumed that these are successfully rolled out to the majority of the population relatively quickly, leading to successful early mitigation of the virus threat and giving actors greater ability to focus on long-term social and economic recovery.

In the second scenario, we considered a partially successful mitigation of COVID-19, where there remains a persistent but manageable health threat - perhaps due to reduced effectiveness or slow uptake of vaccines, transmission via national and international travel corridors or challenges keeping pace with virus mutations.

In the final scenario, we examined the effect of a more prolonged and severe social and economic crisis, where significant disruption is felt for some time even if the immediate health threat in the UK from COVID-19 declines. Such a prolonged crisis might stem from global asymmetries in mitigation efforts, mutation of the virus or the compound effect of protracted complexities arising from new arrangements following Brexit. 


\subsection{Place, scale and time}

The dimensions of place (locality, physical and social context), scale (individual, community, regional, national) and time (past, present, future; short, medium and longer term) help us to understand and respond to the fact that, while we may all be in this crisis in one way or another, we are not 'all in this together'. Some people - on account of who they are, where they live, how visible they are to decision-makers and how long they will face the pandemic's effects - are much more deeply impacted than others. Thus, when considering the dimensions of place, scale and time we are also considering the people and relationships these dimensions influence. In this report, our findings and recommendations make frequent reference to these three critical dimensions, which contextualise our conclusions:

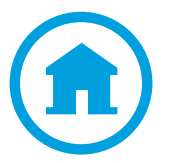

Place is an essential part of grounding the policy response in crucial knowledge from citizens, communities and cultures, to improve the sensitivity of decision-making to the distinct challenges and opportunities for different places.

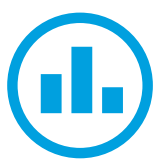

Scale features in our analysis of the complex interconnections between the levels of decision-making - from individual choices and behaviours right up to international and global relations - and the relations of power and influence within and between them.

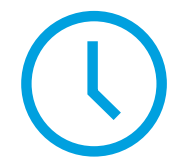

Time is embedded in our commentary on how we acknowledge and learn from history, and how we consider the length and stages of recovery and when and over what timescale different interventions should be made.

In the next chapter we present our findings on the strategic goals and future considerations for policymakers, the evidence which supports them and illustrative examples of practical policy opportunities. 

Our intention is both to highlight these options for consideration and to stimulate discussion among decision-makers over the practical steps that can be taken towards each policy goal. It is possible to begin the journey along some of these avenues in the immediate term, whereas others may require a slower start and more preparation to cross complex territory.

\subsection{Build multi-level governance structures based on empowering participation, engagement and cooperation to strengthen the capacity to identify and respond to local needs}

\subsubsection{Overview}

Whether focusing on the recovery or improving our responsiveness and resilience to future crises, policies and decisions must be made and implemented at different levels of governance - and for them to work most effectively, these levels must operate in strong partnership, with both vertical and lateral collaboration.

While the tensions between localised and centralised governance are longstanding, the current crisis has highlighted both clear justification and a unique and powerful opportunity for a thorough, transparent and bipartisan assessment and reform of the role and powers of central and local governments - and, crucially, how they interact across a range of policy issues and areas of service provision.

Multi-level governance must work vertically and laterally, so both scale and place are essential dimensions. Mechanisms must be in place to ensure that the specificities of different localities are fed upwards to help contextualise policy and grant the appropriate level of autonomy, while national-level support feeds back down for effective place-based intervention. Equally, different bodies at the same level such as different local councils, government departments, health trusts and local enterprise partnerships - must be able to learn from each other, share evidence and resources and provide lateral accountability to help improve policy responsiveness to diverse and changing local needs.

\subsubsection{Evidence}

There is strong evidence that tensions and inconsistencies between different levels of governance have affected the coordination and effectiveness of the policy response to COVID-19. A legacy of longstanding and unresolved issues and disagreements over the best models for devolution and decentralisation have undermined policy coherence, particularly in times of crisis. The COVID-19 crisis can offer policymakers at all levels lessons on effective coordination and delineation of responsibilities and help determine the right balance between local autonomy and national standardisation. ${ }^{5}$

Evidence from history suggests that specific, resourced local and community knowledge, including within local government, is vital to combating and recovering from epidemics. ${ }^{6}$ Analysis of previous health crises has shown that the relationships between different levels of governance are essential in 
coordinating a national response and tailoring it to the unique contexts of different localities. Capabilities - and the ability to connect and work together seamlessly to link data, analysis and people - are as important as the capacity to do so. For example, the structural challenges of the swine flu epidemic, particularly the confusion between agencies at a local level and disagreements over communication strategies, have been shown to have hindered containment of the outbreak.

In addition to multi-level governance within the UK, the layers of international levels of governance are important as well. The UK has historically operated within a nexus of international agencies in epidemics and public health crises (such as HIV/AIDS) and played a significant role in shaping the policies and responses of those agencies, including the World Health Organisation and EU agencies. ${ }^{8}$

Independent assessment of recent public health reforms has suggested that, while there has been greater local innovation and some pockets of integration, cuts to local authority budgets have severely hindered their ability to lead on public health activities and led to fragmentation of commissioning and provision. These local budgetary constraints have been exacerbated by the COVID-19 crisis, and revenue streams are unlikely to keep up with demand for and cost of services. Extra local government funding, greater pooling of resources and joint commissioning have been recommended as ways to address this in public health. ${ }^{9}$

Local government revenue streams in the recovery period are unlikely to meet rising costs as demand for local service provision increases..$^{10}$ Many experts and organisations, including the OECD, are recommending that central governments work with their devolved and local counterparts to find ways to reduce the gap between decreasing revenue streams and increasing costs of service provision in devolved and local administrations."

Trust in central government and in politicians generally, despite showing a longterm slow decline, is quite responsive to national- or international-level events, but through this pandemic we find that trust at more local levels (such as in local MPs or local authorities) tends to be higher and more stable than trust in central government. Therefore, national strategies to deal with the crisis and mitigate its effects are likely to have greater success if interpreted, reinforced and implemented at the local level, by local agents and institutions. However, this can place greater pressures on local government as the first port of call for the public, and local authorities must be adequately resourced and given the right support from the centre to take on these responsibilities. ${ }^{12}$

Insights and techniques for responsive and adaptive multi-level governance are being developed and successfully implemented to support the recovery from COVID-19. Joined-up decision-making to accommodate uncertainties, such as climate change and technological change, is helping to inform key local infrastructure planning - as seen, for example, in the collaborative project between the University of Leeds and Transport for Greater Manchester to build flexibility into

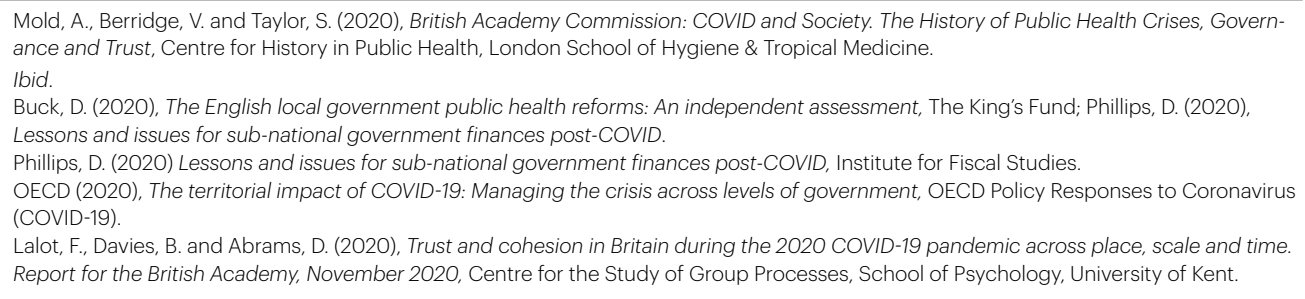


their COVID-19 recovery plans. ${ }^{13}$ The success of responsive local partnerships during lockdown, such as the Area Action Partnerships in Durham, ${ }^{14}$ is another example of effective joined-up decision-making that could be used going forward to tackle key local issues (such as local skills shortages) or to support community-level public health initiatives.

The current fiscal borrowing and reserved powers settlement for devolved governments has not provided enough flexibility for each administration to manage the crisis effectively and places limitations on the role these governments can play in the recovery. The Barnett Formula remains a blunt tool; the COVID-19 crisis has developed differently in each of the four nations because of demographic, social and economic differences, and this has required spending levels that do not correspond to the simple population-based formula. ${ }^{15}$ Short-notice decisions and revision of the funding by Westminster during the crisis also led to uncertainties which hindered planning in devolved governments. ${ }^{16}$ Specific contexts will mean the recovery across different parts the UK will require a more tailored and multi-year approach to funding.

In addition to the fiscal issues, institutional arrangements for constructive intergovernmental relations between the UK and devolved administrations have been inadequate, and this has contributed to the divergence and inconsistency in responses to the crisis. ${ }^{17}$ There was already a need to facilitate better dialogue between the UK's four administrations after Brexit; doing so now could help to restore trust and contribute to more effective governance across the UK in the recovery from COVID-19 and beyond..$^{18}$

\subsubsection{Policy opportunities}

- Consider steps towards a more agile devolution and decentralisation settlement, taking into account the needs and desires of different places to take up greater autonomy and freedoms at different speeds.

- Support local authorities to generate higher levels of autonomous funding, considering the pros and cons of a range of options - such as re-evaluating council tax property bandings or increasing the local share of business rates revenues. Central government should work closely with local governments to evaluate carefully, and agree, the appropriate fiscal levers.

- Explore options for sharing and redistributing funding between local authorities, and reassess the balance between central and local funding for local public services on the basis of local needs and capacities. It may also be advantageous to keep the funding formula under frequent review, so that it is more responsive to geographical inequities in funding distribution as the economies and demographics of places shift.

- Address confusion over relationships between NHS, central public health agencies and local government public health, including social care, with stronger emphasis on joint commissioning of services, pooled resources, place-based strategies and strengthened local leadership to help drive innovation.

\footnotetext{
Roelich, K. (2020), Submission from the Sustainability Research Institute, University of Leeds, British Academy Covid and Society Call for Evidence.

Morrison, E., Fransman, J. and Bulutoglu, K. (November 2020), The social implications of Covid-19 on communities, The Institute of Community Studies, The British Academy Covid and Society Review, p.19.

Phillips, D. (2020) Lessons and issues for sub-national government finances post-COVID.

Cheung, A. (2020), 'Barnett Formula', Institute for Government, [accessed 10 March 2021].

Kenny, M (2020), 'Why have the UK's governments diverged on easing lockdown?', Bennett Institute.

McEwan, N. Kenny, M., Sheldon, J. and Brown Swan, C. (2020) 'Intergovernmental Relations in the UK: Time for a Radical Overhaul?', The

Political Quarterly, 91(3), pp. 632-640.
} 
- Consider greater joined-up use of decision-making processes that accommodate uncertainty, such as robust decision-making (RDM) and adaptive decisionmaking $(\mathrm{ADM})$, particularly when developing strategies for infrastructure investment and key service provision.

\subsection{Improve the way we develop, share and communicate knowledge, data and information to enable all decision-makers to work from shared understanding of the facts}

\subsubsection{Overview}

The quality and consistency of the flows of information within government, between different departments and agencies and between government and non-state actors (including the wider public) should be improved significantly if the country is to mitigate the social effects of the COVID-19 crisis and be prepared effectively for future crises.

The flow of data and evidence is a crucial aspect of communication. Decision-makers need to make data sharing with other agencies the default position, including at international levels when appropriate, and even more actively during a crisis, as a more coordinated and shared view of the facts is in the public interest.

Efforts should be taken to make communication more of a two-way process, informing while also engaging people and organisations to participate by feeding back information, with greater transparency of sources to improve trust - and efforts to address the different ways in which different societal groups receive and consume information. Communication needs both to reflect and to learn from people's lived experience and to go beyond simple information sharing.

\subsubsection{Evidence}

The response to the pandemic and its unfolding effects has shown that 'there is a need for better understanding, use and integration of knowledge in policymaking from different sources and types of data and evidence..$^{19}$ The effectiveness of communication of information about the virus and the measures taken to tackle the pandemic is critical for avoiding negative health behaviours and outcomes. Research on pandemics throughout history - from those studied by Thucydides, to the Black Death, to HIV/AIDS - has demonstrated that pandemics are complex, and policy interventions must be multidisciplinary and intersectional in response. ${ }^{20}$

Knowledge of how interdisciplinary insights can be integrated is essential, in particular, how SHAPE and STEM disciplines come together coherently to inform policy and shape better outcomes. Data linkage, governance and learning across contexts is particularly critical to resolving long-term, interconnected societal impacts. ${ }^{21}$ We need to examine social dynamics linking medical, social and economic factors and social resilience: 'Effective action requires understanding the connections between economic, social, and bio-medical factors as a dynamic system

Morgan Jones et al. (2020), 'Shape the Future', p. 170

'Ibid', p. 253.

Abrams, D. Hand D.J. Heath, A. Nazroo, J. Richards, L. Karlsen, S. Mills. M. Roberts, C. and the Centre for Homelessness Impact (2020),

What Factors make a community more vulnerable to COVID-19? A summary of a British Academy Workshop, The British Academy; Leyser.

O. and Richardson, G. (2017), Data management and use: governance in the 21st century, The British Academy and The Royal Society. 
and not to privilege one above the others. ${ }^{22}$

Lack of information or, conversely, the spread of disinformation, carries associated health risks, a situation we have seen unfold in many different health crises over the years ${ }^{23}$ and which is gaining increased attention in relation to vaccine hesitancy. ${ }^{24}$ Some of the well-known examples where this has gone wrong relate to public health vaccination campaigns (notably MMR), but what is less well known are examples where integrated, joined-up, and -locally rooted messaging that built on and worked with community knowledge and expertise worked well to rebuild trust and confidence. For example, when vaccination rates for whooping cough (pertussis) fell in the mid- to late 1970s, the Government worked hard to restore trust in the vaccine and worked with voluntary organisations to develop tailored public health messaging. ${ }^{25}$ Similarly, analysis of the 1985 public health campaign 'Heartbeat Wales' showed that public beliefs about the causes of heart disease were a complex mixture of evidence from official advice, media messages and the lived experiences of people in local communities. Deep understanding of how to maximise the opportunities of 'lay epidemiology' was crucial to the campaign's eventual success. ${ }^{26}$

As we look to the past it is also worth bearing in mind that elements of public health crises are always unpredictable, so planning must be responsive and adaptive. Memories of previous crises are known to structure responses to current ones, but institutional memory nonetheless fades over time. ${ }^{27}$ Evidence suggests it is crucial that we integrate and incorporate this understanding for future crises.

Research from the Reuters Institute has found that 'foregrounding highly and broadly trusted expert sources who demonstrably help people understand the crisis could help enhance public engagement, understanding, and trust overall. It might even help reach the infodemically vulnerable, who trust the NHS and various experts less than do the public at large, but far more than they trust news organisations or the government. ${ }^{28}$ Early findings from community-based research networks across the UK are showing that there is a significant amount of desensitisation to news, media and information, leading many individuals to rely on personal strategies, often related to local behaviours. ${ }^{29}$

The link between trust and the way in which information is collected, integrated, used to inform decision-making and then disseminated and handled is significant. Research tracking trust in government in response to the COVID-19 crisis showed that, as with general political trust, measures of trust related to COVID-19 revealed a gradual linear fall from May 2020 onwards, with small fluctuations but a general downward trend for the rest of the year. The researchers conclude that 'it is quite doubtful that further crisis will necessarily generate the same level of trust as people reflect on their disappointment from the first time around'. ${ }^{30}$

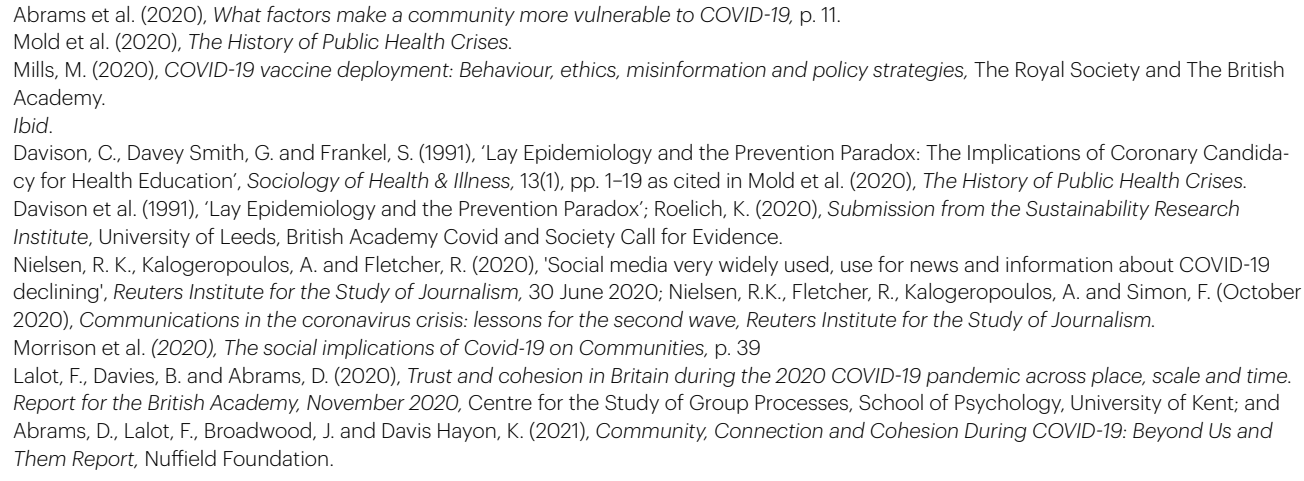


All this reinforces the link between evidence, decision-making and health outcomes. Trust is fundamental to ensuring that communications engage voluntary commitment to public good. Communication that is remote and disconnected from people's experiences in place, time or scale has less scope to capitalise on trust. Whereas trust in the UK Government is low there is a substantially higher level of trust in local representatives and authorities, and areas that have invested in social cohesion have sustained and benefitted from higher levels of community trust, supporting their ability to reach vulnerable groups, mobilise mutual aid and counter misinformation. ${ }^{31}$

In addition, the evidence from the past year indicates that government communication and information about the pandemic has not been accessible for many groups in society. Research from the Institute for Community Studies found that information inequalities exist around age, income, location, disability and education where communication is primarily reliant on online services. ${ }^{32}$ There are particular issues when it comes to communicating risk. Risk information during the pandemic has often been presented without thought to how cultural values and linguistic diversity affect interpretation. As an ethnically and culturally diverse country, there is an acute need to adopt more inclusive communication practices. ${ }^{33}$

This makes it all the more important to ensure the effective translation of information into different languages, including braille, sign language and community languages, as well as attention to the ways in which we frame information and the specific words we choose..$^{34}$ In 2015, World Health Organization guidance on naming new infections advised against naming them according to geographic location, people's names, species of animal, or food, or using cultural, population, industrial or occupational references. They advocated the use of language that does not incite undue fear. We only need look at the example of leprosy to appreciate the significance of this; in the past, people with leprosy (and those who were thought to have it) were commonly referred to as 'lepers', a word which retains a strongly derogatory meaning today. ${ }^{35}$

We have seen through both previous research and current experience that the nature of expertise is 'fluid, varied, and contingent on new evidence' and it is expressed as 'possibilities and probabilities, not certainties' ${ }^{36}$ Policymakers often have to deal with the former, and the incentive structures of systems which deal in certainties versus those that allow for possibilities are not always in alignment, particularly in times of crisis. The policy opportunities below provide examples of how this goal might be achieved and alignment in these structures sought.

\subsubsection{Policy opportunities}

- Work towards improved, evidence-based, cross-linguistic and cross-cultural health communication at different levels, including the international where appropriate, both to improve future pandemic response and to reduce health inequalities.

- Consider ways to improve the institutional memory of past crises and use this to

Lalot et al. (2020), Trust and cohesion in Britain during the 2020 COVID-19 pandemic across place, scale and time.

Morrison et al. (2020), The social implications of Covid-19 on Communities.

Tang, C. (2020), 'British Academy Covid and Society Evidence Call', 21 December 2020

Morgan Jones et al. (2020), 'Shape the Future', p. 241; Dowd, J.B., Ding, X., Akimova, E.T. and Mills, M. (2020), Health and inequality: The

implications of the COVID-19 pandemic, Leverhulme Centre for Demographic Science, University of Oxford.

Morgan Jones et al. (2020), 'Shape the Future', p. 241

'Ibid', p. 171. 
help improve the communication of decisions how to communicate decisions, including learning from different regions, cultures and countries.

- Strengthen data linkage within and across government agencies (particularly across health and social data) and improve data access for external accredited experts and researchers on a more ongoing basis.

- Consider ways to improve communication of risk, uncertainty and unknowns, particularly in helping to narrow the gap between official understanding of risk and public understanding.

- Explore ways to increase the transparency of the underlying science, research and information for policy decisions in the long-term response to COVID-19, with greater focus on public communications from non-political and widely trusted expert sources to help the public understand and engage with the crisis and the necessary response.

- Take forward options for increasing the breadth and depth of expertise in research, data analysis and communication across local government, for example by considering locally grounded scientific advisory networks and/or analytical capacities in the form of local observatories that bring together local expertise in universities, civil society groups, local government and businesses.

- Find better incentives, support structures and frameworks for social media platforms to tackle the spread of misinformation, and foreground highly and broadly trusted expert sources of information on social media so that they reach groups who tend not to consume mainstream media and official sources.

\subsection{Prioritise investment in digital infrastructure as a critical public service to eliminate the digital divide, improve communication and joint problem solving, and create a more equitable basis for education and employment}

\subsubsection{Overview}

Successful recovery demands that the country prioritises and accelerates its investment in digital infrastructure. The lockdown has created an opportunity to embrace digital technology in enhancing the way we do things, but it has also highlighted disparities in digital access and heightened the need to ensure no people, groups or places are left behind by the rapid changes in the way people live, work and learn.

The existing geographical and socioeconomic inequalities in digital access across the country should be tackled as they remain a primary barrier to levelling up. Addressing digital infrastructure needs is a necessary initial step to tackling the structural inequalities exacerbated by the pandemic in a meaningful way, but by no means the only step. There is also a clear need to consider place-based approaches to upgrading digital infrastructure, understanding the priority needs of local areas to create equity.

The issue is so fundamental that government and other actors ought to treat investment in digital infrastructure as a critical, life-changing public service, taken forward with the same zeal that we saw in 19th-century Britain with the railway boom, or in the 20th century, the construction of the national grid. 


\subsubsection{Evidence}

The pandemic has revealed inequalities in digital access across regions, which has implications across a range of areas including employment, ${ }^{37}$ education, ${ }^{38}$ and social infrastructure. ${ }^{39}$ Improving digital access can help address an integrated raft of these types of effects. These effects are also, in many cases, strongly linked to existing income and educational inequalities, and responding to these inequalities (as discussed at 3.5 and 3.7) could help by making access to digital equipment and services more affordable to households and improving digital literacy.

Early evidence shows a disproportionate effect of the pandemic on income inequality, particularly in those areas where inequalities already existed -including gender, socioeconomic and labour inequalities. Due to the changing effects of the pandemic on the labour market, improved digital infrastructure could mitigate continued exacerbation of these inequalities. For example, parents - and especially mothers - seeking work or employment were disproportionately affected by nursery closures and caring responsibilities. ${ }^{40}$ In the longer term, effects on labour market opportunities could limit the ability to pay for childcare, further exacerbating effects on women in the labour market. However, opportunities which remote working could provide may offset these, but will rely on improved and more equitable access to digital infrastructure. ${ }^{41}$ The increased ability for people to work from home could also have important implications for people searching for work over a wider geographical area. ${ }^{42}$

With regard to education, evidence synthesised by the Institute for Fiscal Studies for this review shows that during the pandemic, children from higher-income households are more likely to have online classes provided by their schools, spend more time on home learning and have access to resources such as their own study space..$^{43}$ Children whose parents are out of work are much less likely to have additional resources such as computers and tutors. ${ }^{44}$ The disproportionate effects of these existing socio-economic inequalities, particularly as played out through digital access, will have long-term effects and widen income and socioeconomic inequalities. Previous work has shown that 'the relatively low educational performance of children from poorer backgrounds is an important reason for decreased levels of intergenerational income mobility.. ${ }^{45}$

Evidence also shows the importance of digital access as a component of social infrastructure and social capital. In the first national lockdown, community support and mobilisation were heavily mediated and affected by digital infrastructure and access. 'WhatsApp appeared to be the principal organising platform for mutual aid groups ... established community groups worked primarily with Slack, through email and Zoom and through physical leafleting to reach those digitally excluded. ${ }^{36}$

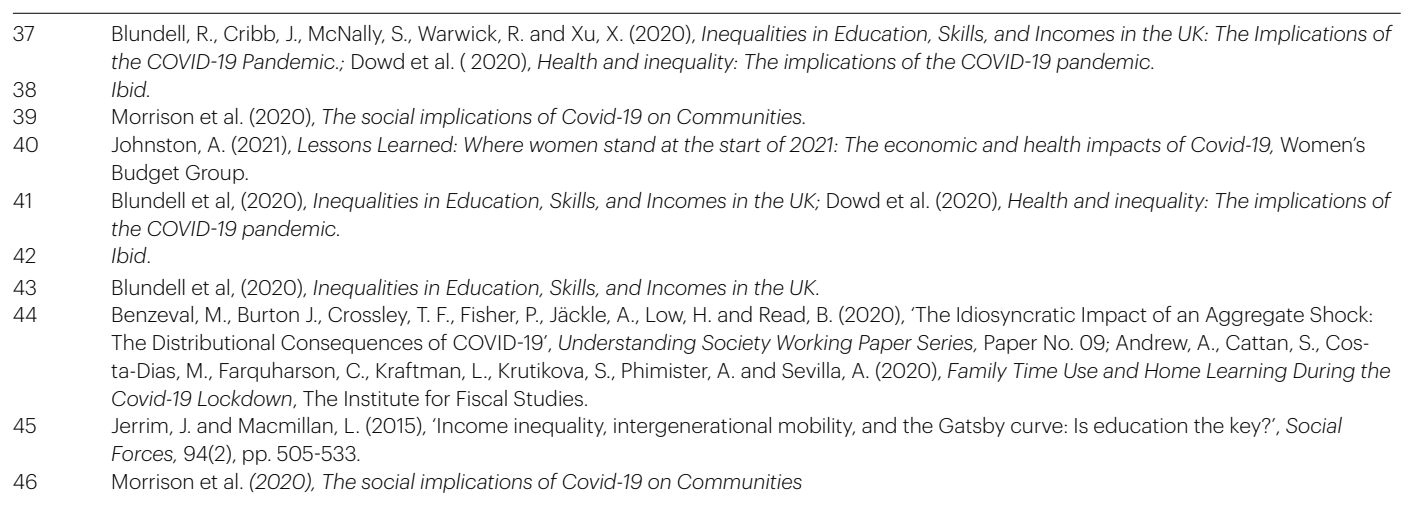


Small businesses and social enterprises, as well, have been shown to be crucial to the recovery, but SMEs argue that they are disproportionately impacted by slow roll-out of critical digital infrastructure, notably full-fibre broadband. ${ }^{47}$

\subsubsection{Policy opportunities}

- Accelerate the roll-out of full-fibre broadband to the whole of the UK by reaffirming commitment to the pledge for completion by 2025 and ensuring the appropriate investment, incentives and policies are put in place to meet this, learning from successes in other countries.

- Consider adopting more place-sensitive approaches to upgrading digital infrastructure, so that the priority needs of local areas are better accounted for and can be more effective in tackling existing inequalities.

- Consider options for making a basic level of fibre broadband accessible and affordable to all households and improving the availability of fast and secure public internet access in local communities as a means of addressing the most urgent issues and inequalities in digital access.

- Explore ways to improve the data handling systems of local governments and agencies, incentivising opportunities to pool resources and share high-quality digital platforms. This could help improve the quality, efficiency and resilience of local service delivery as well as enhance public engagement and trust.

- Support the translation of knowledge between researchers, educational professionals and the EdTech industry to improve digital technology and resources for education and ensure schools and colleges can confidently invest in new technology and better digital services. Improvements in this area can help tackle educational inequalities and improve the overall quality of education.

- Explore further the opportunities for deploying digital technology in the provision of public services. In the justice system, for example, such technology can assist in reducing the court backlog created by lockdown and delivering greater efficiency and equality of access for the future.

\subsection{Reimagine urban spaces to support sustainable and adaptable local businesses, amenities and lifestyles}

\subsubsection{Overview}

The effects of the pandemic provide a crucial thrust to rethinking the relationship between urban, rural and other environments with a more efficient and sustainable future in mind. Central and local governments must come to a consensus around a comprehensive but place-sensitive land use plan that creates a viable blueprint for the development of flexible, sustainable neighbourhoods, towns and cities.

The hollowing out of town centres should be reversed by developing technologyrich flexible workspaces and nature-based solutions to future retail, commerce, leisure, transport and tourism. This will be contingent on progress made on digital infrastructure, as set out in 3.3. 
Drawing on the importance of building multi-level governance (see above at 3.1), decision-making needs to balance local autonomy with ensuring local planning decisions are in tune with national and global sustainable development goals.

The regeneration of towns and cities will need a range of skills that offer new educational and employment opportunities, helping to transition the economy to sustainable growth. It will also protect society and the environment against unsustainable urban-to-rural migration and suburban sprawl, which could have devastating environmental, cultural and social consequences and could make the country's commitment to achieving net-zero all the more difficult.

\subsubsection{Evidence}

The pandemic has created 'push' and 'pull' factors for migration out of cities and towns, including the urban concentration of COVID-19, demand for green spaces, less reliance on the high street, unemployment and financial pressures and greater flexibility for office-based workers to work remotely.48 Survey data suggests that around $14 \%$ of Londoners want to leave the city because of the pandemic. ${ }^{49}$ It would take the action of only a small proportion of those considering moving to reverse net rural-urban migration trends and see an accelerated decline in urban density and greater urban sprawl. Yet density itself is not directly associated with the higher COVID-19 infection and death rates in cities: this has been shown to be more likely the result of structural inequalities and the specifics of COVID-19 response measures.50 In fact, there is some evidence to suggest that denser cities will be more resilient to future health crises if they are efficiently and equitably designed. ${ }^{51}$

Maintaining urban density is an essential part of creating more efficient, economically productive and sustainable towns and cities. Behavioural changes during lockdown, such as increases in walking and cycling for local travel, greater use of public parks and green spaces, and consuming local produce, offer opportunities for sustainable urban redevelopment which supports healthier and greener behaviours while encouraging people to remain living and working in denser urban communities. ${ }^{52}$ These changes have accelerated interest from urban developers to invest in new projects, such as the £5billion joint venture between Related Companies and Argent to create a 15-minute city, Brent Cross Town, in north London. ${ }^{53}$

Consumption patterns have changed considerably because of lockdown restrictions and this has highlighted weaknesses in the efficiency and sustainability of food systems. There was already well-documented evidence of food waste as a societal issue that contributes to a range of negative impacts such as increased greenhouse gas emissions, water shortages, biodiversity issues, price inflation and food insecurity. Subsequent research over the lockdown period has revealed positive behavioural changes, with increasing consumer awareness of food waste issues

London Assembly Housing Committee, (2020) 'Half of Londoners wanting to move home want out of London'; PwC (January 2021), UK Economic Outlook.

50 Sharifi, A. and Khavarian-Garmsir A.R. (2020), 'The COVID-19 pandemic: Impacts on cities and major lessons for urban planning, design, and management', Science of the Total Environment, 749.142391; Carozzi, F., Provenzano, S. and Roth, S. (2020), 'Urban Density and Covid-19', London School of Economics and Political Science Centre for Economic Performance, Discussion Paper No 1711; Connolly, C., Keil, R. and Harris Ali, S. (2020), 'Extended urbanisation and the spatialities of infectious disease: Demographic change, infrastructure and governance', Urban Studies, 58(2), pp. 245-263; and Dowd et al, (2020), Health and inequality: The implications of the COVID-19 pandemic. OECD (2020), Cities policy responses; and Connolly et al. (2O2O), 'Extended urbanisation and the spatialities of infectious disease'. ARUP (2020), COVID-19 Mobility Insights: Rebuilding Resilient Cities; Goodair, B. Kenny, M. and Marteau T.M. (2020), Townscapes: England's Health Inequalities, Bennett Institute for Public Policy; and Morgan Jones et al. (2020) 'Shape the Future'. Bloomfield, R. (2020), 'London Development to Test Demand for 15-Minute Cities After Covid-19', Wall Street Journal, 22 December 2020 see also Brent Cross Town, (2021), A Park Town for Future London, [accessed 10 March 2021]. 
and greater willingness to reduce household food waste, with food waste in the UK falling by $43 \%$ in the early stages of the first lockdown and an overall decrease of $27 \%$ between November 2019 and September 2020. ${ }^{54}$ Studies in the US have also suggested that the pandemic may lead to longer-term improvements in household waste skills and management practices. ${ }^{55}$ This presents an important opportunity to help embed positive attitudes and behaviours to ease transition to more sustainable, circular food systems.

Water and energy consumption have also changed, with higher domestic consumption driven by people working from and spending more time at home. If flexible working arrangements continue, it will be necessary both to improve the efficiency of household utility infrastructures and to change consumption behaviours, bringing together strategies on water, food, agriculture, energy and climate change..$^{56}$

Urban economies have been transformed due to changes in high streets, more online consumerism and changed working patterns due to increased working from home, particularly for those on higher incomes. These transformations are place-specific and dependent on regional economics, demographics and physical geographies. Relationships among local businesses, communities and local councils have been imperative to survival, and there is evidence of a consumer shift to support local independent businesses and social enterprises. Such relationships must be maintained and enhanced in planning the recovery of local economies. ${ }^{57}$

Reimaging urban spaces will require smart innovation in planning regulations as well as business rates and local taxation. Changes in both shopping and working habits may continue to reduce the size of the business rates tax base, while the current rates system may make it harder for both businesses and local government to invest in local communities, making reform even more important. ${ }^{58}$

And while lockdown has highlighted the growing value of public spaces, it has also revealed the scarcity of public spaces and parks especially in areas with mostly Black, Asian, minority ethnic or poorer communities..$^{59}$ It is essential that plans for urban redevelopment in the post-crisis recovery take account of the inequalities that exist within and between different urban communities. Building public parks in areas where people have limited access to green space can help to reduce health inequalities. ${ }^{60}$

\subsubsection{Policy opportunities}

- Develop stronger, sustainability-led approaches for urban planning that focus on a just transition to net zero carbon, drawing on the evidence of successful strategies in the UK and abroad and exploring initiatives like hyper-localisation of amenities, green spaces and traffic-free streets.

- Consider the options and incentives for developers as well as large urban

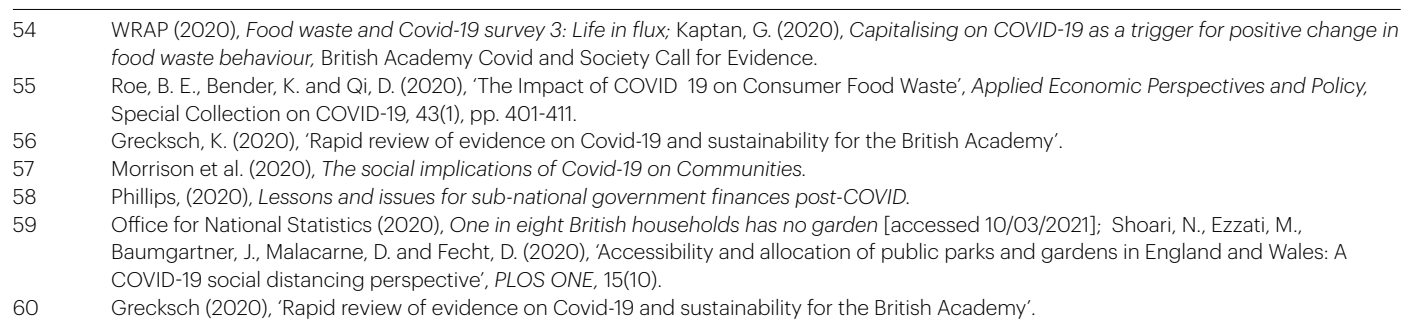


landowners - including churches, local authorities, universities and utility companies - to pursue sustainable land use ventures such as rewilding and public green spaces.

- Rethink business rates and local taxation reform in light of pandemic effects and recovery, evaluating options against the evidence of what supports and incentivises investment in local communities.

- Explore collaborative approaches involving utility providers to develop energy and water efficiency campaigns based on new ways of working and living, to help cement more environmentally sustainable behaviours.

- Consider sustainable and equitable options for redeploying suitable surplus commercial space for affordable housing and community-led projects with social, cultural or educational purposes, to help prevent urban degeneration, benefit from increased urban density and ease pressure to develop greenfield sites.

- Create accessible mechanisms for local communities to engage meaningfully and deploy their local knowledge in planning decisions, with emphasis on empowering underrepresented voices and improving public trust.

\subsection{Create a more agile, responsive education and training system capable of meeting the needs of a new social and economic environment and acting as a catalyst to develop and enhance our future}

\subsubsection{Overview}

COVID-19 has lasting implications for our economy, labour market and communities, which will not be distributed equally but will exacerbate existing employment trends across sectors and geographic communities, and which disproportionately impact the vulnerable. These changes will require rethinking the types of knowledge and skills needed in a new social and economic environment, with an emphasis on using lifelong education and training as a catalyst to develop and enhance our future, while better preparing us for the challenges we could face.

Current cohorts in education have suffered an unprecedented loss of learning opportunities, which has also increased existing educational inequalities. We must consider any remedial measures as part of a coordinated systems-level rethink for improving education and skills.

While educational strategy must be driven by a systems-level approach, policymakers in central government must take account of the different contexts of schooling locally and allow enough flexibility for local actors to review and respond in the most appropriate way on the basis of local knowledge and experience, in partnership with central government and national agencies. Educational institutions themselves have an important, active role to play in shaping an effective and responsive local strategy.

Measures to support reskilling and training to tackle unemployment will need to take place quickly, but other aspects of educational reform will require careful thought and a staggered approach to allow time to collect the necessary evidence, give practitioners time to prepare, and ensure full support and buy-in of the key stakeholders. Now that the education system has been rapidly equipped to deliver many forms of education remotely, there is an opportunity to be seized to distribute the opportunity to learn more widely and for longer, in terms of both the range of provision and its demographic reach. 


\subsubsection{Evidence}

The evidence demonstrates that the immediate effects of the pandemic are likely to increase three types of inequalities, which were already prevalent in society but have been further exacerbated: education and skills, income and intergenerational inequalities. ${ }^{61}$ All of these are interlinked when considered in light of the goal of creating a more agile and interconnected education system that focuses on building skills that can flexibly respond to the new social and economic environments in which we will find ourselves.

Shutting down large parts of the economy and the associated changes to lives and livelihoods will have an effect on the shape of the labour market in future. The sectoral impact of the pandemic is likely to increase income inequalities as low-paid workers are much more likely to work in hard-hit sectors and be unable to work from home. ${ }^{62}$ Addressing the pre-existing income inequalities and softening the likely increase in these inequalities that is often seen during recessions will require dealing with the rise in unemployment and resulting fall in living standards, especially once temporary support schemes are wound down.

As a result, a rethinking of the kinds of skills needed in a new economic and social landscape is required as we also respond to climate change and demands for a greener economy. Some argue that the state has an active role to play in signalling those areas of the labour market and economy that could benefit from a sustained and sustainable influx of people, and that, regardless of other economic outlooks, the state should invest in skills training in health and social care and education. ${ }^{63}$ Other evidence suggests that graduates from arts, humanities and social science subjects are likely to be more resilient and better able to respond to a dynamic and uncertain economy ${ }^{64}$ Still other analyses suggest that the demand for skills will have changed even more than we envisaged before the pandemic, particularly in the health and care sectors as well as in response to new technologies, ${ }^{65}$ and there is likely to be a higher pay-off to investments in skills that complement green technologies among those with lower formal education qualifications. ${ }^{66}$ Regardless, it is clear that a more dynamic and resilient approach to supporting a range of skills that can be deployed effectively and efficiently throughout the education and training system will be needed.

Closely linked to all this are the clear and substantial disruptive effects on education and skills for children and young people. The evidence here is significant and stark. There is well-established evidence that gaps in educational achievement between people of different socio-economic backgrounds are significant even before the start of school and widen over the course of one's educational career. ${ }^{67}$ Moreover, though evidence suggests that this must be tackled throughout the educational cycle, significant investments in human capital are also needed throughout one's working life as learning is cumulative. ${ }^{68}$ As has been noted above and throughout our accompanying report The COVID decade, these inequalities are only being widened

Blundell et al, (2020), Inequalities in Education, Skills, and Incomes in the UK

Blundell et al, (2020), Inequalities in Education, Skills, and Incomes in the UK; and Dowd et al. (2020), Health and inequality: The implications of the COVID-19 pandemic.

Ibid.

The British Academy, (2020), Qualified for the Future: quantifying demand for arts, humanities and social science skills.

Smith, B., Hopkins, C., Whitcroft, K., Kelly, C., Burgess Watson, D.L. and Deary, V. (2020), Covid and Society: Accessing Healthcare before, during and after the pandemic, School of Advanced Study, University of London.

Blundell et al, (2020), Inequalities in Education, Skills, and Incomes in the UK; Smith et al. (2020), Covid and Society: Accessing Healthcare before, during and after the pandemic.

Feinstein, F. (2003), 'Inequality in the Early Cognitive Development of British Children in the 1970 Cohort'. Economica, 70, pp. 73-97; Hansen, K. and Hawkes, D. (2009), 'Early Childcare and Child Development', Journal of Social Policy, 38, pp. 211-39. 
through the effects of the pandemic, and concerted attention, linked to a responsive skills strategy, is required. For example, evidence shows that as disadvantaged students are more likely to go to further education colleges, there is some justification for additional resources being allocated to these institutions to enable flexibility as well as providing for additional remedial tuition for entry cohorts most affected by COVID-19. ${ }^{69}$

Further education colleges are also likely to be heavily involved in delivering the reskilling agenda pledged by the Government as part of a package to mitigate unemployment and address pre-pandemic concerns over productivity in a changing economy. High-level skills will continue to be in demand-from the creative arts and entertainment sector, to financial services, health and social work - and ensuring that provision is able to keep pace with demand will require attention to funding and access. $^{70}$

As the country may be facing increasing levels of unemployment, particularly in the short to medium term, it is also worth noting that unemployment has been linked to more self-destructive health behaviours, such as smoking, increased alcohol consumption, and poor diet, which lead to outcomes such as weight gain, cardiovascular diseases, diabetes, cancer, and a range of mental health problems. Particularly for youth, who are the hardest hit, this can have life-long health consequences. Retraining, education, apprenticeships, volunteering and related community programmes to keep those who become unemployed active and connected to society will enhance health and avoid longer-term high health costs. ${ }^{71}$ Related, we know that education is not just a learning experience but a social one, in which people make and build relationships, develop skills in working with others and can gain a sense of achievement and purpose. All these elements must be considered part of a coherent and joined-up approach if we are to realise a stronger future.

There are severe and/or distinct implications of the lockdown for specific groups of children and young people, including children living in homes where domestic abuse is present, children who are estranged from their families, those LGBT young people who have a difficult relationship with their families, and children with parents in prison whom they are unable to visit. Children with special educational needs and disabilities (SEND), or education, health and care plans may face particular challenges with remote schooling or may be struggling partly due to having experienced higher levels of anxiety even before COVID-19. There is growing evidence that sustained support will be required to help disadvantaged pupils catch up after they return to school. While a focused catch-up programme - including assessment and targeted support - would be beneficial when pupils first return to school, it is unlikely that a single catch-up strategy will be sufficient to compensate for lost learning due to school closures. ${ }^{72}$

However, some children have experienced positive impacts of lockdown. For children who had been experiencing bullying at school, and for some children for whom education provision and practices have previously not met their needs, the lockdown may have resulted in reduced anxiety through not having to attend school. This raises questions about which aspects of the education system we want to reconstruct as they were, and which aspects need to be constructed differently. ${ }^{73}$

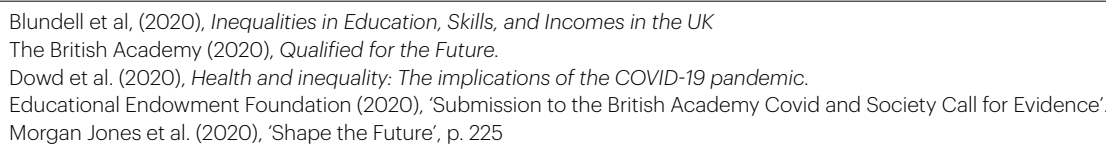




\subsubsection{Policy opportunities}

- Consider a more joined-up policy approach across government departments focusing on children and young people to support their experiences in childhood and adolescence as well as their chances later in life, spanning education, health and social care, employment, crime and policing, community support, and rental and housing policy.

- Retrain people who have fallen out of the labour market, with a clear focus on the future economy we want to underpin our society. This should be part of reaffirming strong general commitment to lifelong learning but include a focus on improving digital literacy and specific training programmes to support key recovery sectors (such as new technologies, green innovation and health and social care).

- Reconsider the breadth of the school curriculum so that new graduates are able to respond to shifting labour market structures throughout the recovery and employ multidisciplinary knowledge and skills in rapidly changing social, economic and technological environments.

- Explore ways to improve flexibility for those currently in education and training to change courses in light of the shifting economy, and ensure adequate funding, particularly in further education, for students to stay in college longer to accommodate retraining and broadening of skills.

- Consider a major overhaul of the qualifications system to ensure it is both futureproofed and sensitive to the loss of education and examination preparation of existing cohorts.

- Ensure the continued widening of access to tertiary and adult education with strong commitment to lifelong learning as part of measures to address educational inequalities. This will require steps to safeguard the financial sustainability of further and higher education providers.

- Look at ways to provide additional opportunities for children to catch up on physical, social and emotional development, with a particular focus on sustaining strong early years provision.

\subsection{Strengthen and expand community-led social infrastructure that underpins the vital services and support structures needed to enhance local resilience, particularly in the most deprived areas}

\subsubsection{Overview}

Community-led social infrastructure has been an essential but precarious lifeline in the crisis, and its importance will only grow as we look to respond to and mitigate the long-term societal effects. These infrastructures must be further supported and enhanced if we are to rely on them in the future.

The pandemic has laid bare the inequalities that exist between different communities, and how some communities have struggled to meet even the most basic needs of their members. This forces us to confront the place-based weaknesses in the support safety net and how these weaknesses tend to align with longstanding geographical patterns of socio-economic inequality.

Although people are often strongly connected to virtual or geographically distributed communities, the most stable and continuous social reality is likely to be where they 
live or work. We must also look more closely at the critical role of these communities in establishing and rebuilding trust and cohesion after the crisis, ensuring the right infrastructure is in place to strengthen trust both within and between different groups and communities, which in turn builds social capital and underpins wider recovery demands for greater economic productivity and resilience. Important civic institutions such as schools, colleges, universities, places of worship, libraries, museums, and sports clubs - all need to act as nodes in the underlying structures that support and empower communities.

The advancement of the role of community-led infrastructure will rely heavily on the developments in multi-level governance and joining up decision-making and resources with decentralised local knowledge and practices (see 3.1), as well as the participation of community-led infrastructures in the redesign of public spaces and amenities to better serve communities (see 3.4).

\subsubsection{Evidence}

Prior to COVID-19, communities in the UK could arguably be seen as being in a state of flux. ${ }^{74}$ On measures such as social relations, cohesion and identity and individuals' sense of attachment to the 'social' dimensions of community there have been changing dynamics. Evidence points to a decline in a sense of belonging and a 'loss' of material components of community. ${ }^{75}$ An increase in mobility and more transient communities also contributed to this, in addition to a demonstrated variability in the social fabric of communities. ${ }^{76}$ This loss was taking place within a space of growing societal uncertainty, a rise in inequality and a decline in trust in institutions. ${ }^{77}$

This makes it all the more important to note that since the start of the pandemic, we have seen that local and hyper-local charity, voluntary and mutual aid groups were key to communities pulling together to help each other, particularly in the early response to the pandemic. ${ }^{78}$ Effective community-led responses have been underpinned both by established, funded community infrastructure and by voluntary engagement by individuals. ${ }^{79}$ Evidence submitted to us showed there is real enthusiasm to continue these forms of engagement and to look at how some of the partnership models utilised during COVID-19 can be adapted during the recovery phases, particularly in relation to preventative place-based initiatives. ${ }^{80}$

But the community response also led to inequalities: less affluent communities with less social capital have had weaker community infrastructures and performed worse in the crisis. There was a positive correlation between the number of Mutual Aid Groups per 10,000 people and measures of socio-economic advantage, such as gross disposable household income per head, or the share of individuals with an undergraduate degree or above, as well as the median wage. The correlation was also positive, with positive effects on wellbeing measures. ${ }^{81}$

COVID-19 has also made highlighted that there are variable levels of deprivation within neighbourhoods, which are not necessarily observable in regional trends or

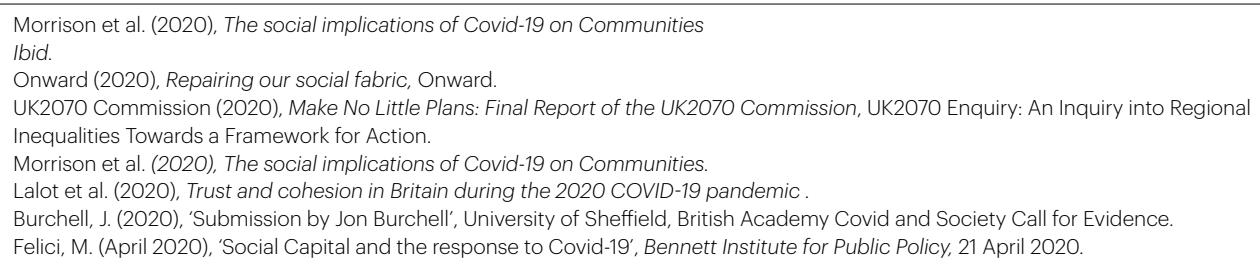


metrics of prosperity such as GVA. This type of analysis and additional insight could have implications for the ambitions to level up across and within regions, and how interventions are structured..$^{82}$

The pandemic has exposed the precariousness of the social security safety net in times of crisis; community organising had to step in to meet basic needs of food, sanitation and financial provision as well as wider wellbeing issues like social connectivity and combating isolation. ${ }^{83}$ This may not be sustainable in future. Research suggests that the needs of different groups may be best met by decentralising public health provision and improving local health services, fixing complex and inefficient governance and regulation in health and social care, and rethinking the structure and funding of social care. ${ }^{84}$ There is a significant risk related to reduced funding for charities and due to challenges for local government finances. ${ }^{85}$

All this is consistent with the finding that locally based trust and connection are consistently stronger than nationally based aspects and represent a vital resource. ${ }^{86}$ Trust is a key contributor to the creation of social capital and plays an important part in generating economic productivity ${ }^{87}$ However, despite an initial crescendo of national solidarity early in the pandemic, many intergroup divisions and tensions are re-emerging and require attention. ${ }^{88}$ Social cooperation can be motivated by trust or by fear, and in a democracy the former is preferable to the latter. Thus, whether cooperation is needed to respond to an emergency, to preserve the environment, to volunteer as a school governor, to leave park gates unlocked, to pay in advance of receipt of goods or even to give credit, it is a vital ingredient of social cohesion and our collective capacity to achieve shared goals. ${ }^{99}$ Preventing and repairing social fractures is therefore not just desirable but essential for a prosperous and successful future and, for this reason, an important avenue for policy. ${ }^{90}$

\subsubsection{Policy opportunities}

- Consider an extended period of targeted transitional funding that would enable local civil society organisations to take on larger and stronger roles while they address deficits in their revenues caused by COVID-19.

- Develop strong, decentralised and inclusive partnerships across multiple sectors and services at a local level, bringing together different service providers to tackle local needs in innovative and responsive ways, with particular focus on tackling inequalities and supporting vulnerable groups.

- Improve mechanisms for the voices of groups often marginalised in policymaking, such as children and young people, to be meaningfully heard in the development of community services. Programmes that build on volunteering, connecting across generations and enabling work experience can help to ensure continued interaction and active populations.

Morrison et al. (2020), The social implications of Covid-19 on Communities, p. 26; as originally cited by WPI Economics for the Covid Recovery Commission, 2020

Ibid.

Davison, C. et al. (2020), 'Lay Epidemiology and the Prevention Paradox'; Buck (2020), The English local government public health reforms. Morrison et al. (2020), The social implications of Covid-19 on Communities.

Lalot, (2020), Trust and cohesion in Britain during the 2020 COVID-19 pandemic

Coyle, D. and Lu, S. (2020), 'Trust and Productivity Growth - An Empirical Analysis', Bennett Institute Working Paper.

Lalot, (2020), Trust and cohesion in Britain during the 2020 COVID-19 pandemic.

Abrams, D. (2010), Processes of prejudice: Theory, evidence and intervention, Equalities and Human Rights Commission, Research Report 56, Centre for the Study of Group Processes, University of Kent.

Abrams, D. and Vasiljevic, M.D. (2014), 'How does macroeconomic change affect social identity (and vice versa)?: Insights from the European context', Analysis of Social Issues and Public Policy, 14(1), pp. 311-338. 
- Explore options for establishing and maintaining structures that build positive relationships within and between groups and communities, equipping and motivating all to cooperate and provide mutual support, including cross-linkages between, for example, schools, local services, colleges and/or universities, and public health organisations that help embed the reality of shared space and opportunity as part of a community.

\subsection{Empower a range of actors, including business and civil society, to work together with a sense of social purpose to help drive a solid strategy for recovery across the economy and society}

\subsubsection{Overview}

The significant achievements in social, scientific, technological and cultural innovation during the crisis were not driven by market competition or state direction alone: different actors worked together towards a common goal because of a shared sense of urgency and necessity. If we are to work effectively towards a positive future, we must strive to enhance the collective sense of social purpose and not revert to atomised, adversarial interests.

The pandemic brought out some of the best features of a compassionate, cooperative and innovative society, driven by the shared purpose of responding to the crisis. However, we need to turn these pockets of purpose-driven cooperation during a crisis into a solid strategy for recovery across the economy and society. But thinking around the benefits system will need to change, enabling more flexibility in supporting those who are vulnerable and out of work, if we are going to achieve this.

Every living generation has been affected by COVID-19; we know the impact is too great and the recovery too large and complex to be dealt with through taxation and financial investment alone, and we have a responsibility to future generations to work together in ensuring that they are not left to pay for the consequences. This means we must all play a role, volunteering our own knowledge, time and labour directly into the recovery.

Every small investment of time and effort put to the core purpose of national recovery can help increase levels of trust and support while rebuilding confidence and improving the health and wellbeing of those hardest hit by the crisis.

Government, business, the media and civil society can come together to actively support and encourage individuals to contribute their energies, break down divides and create a sense of national unity and duty akin to that seen in the war effort.

\subsubsection{Evidence}

In the face of a global pandemic, many businesses, including some who have been hit financially in the crisis, have largely accepted that their social responsibility extends beyond generating profit and paying their taxes and have been willing to engage in greater social action. This is in contrast to the 2008-09 global recession, in which firms withdrew from their corporate social responsibility efforts to focus on profit. ${ }^{91}$ With the steady erosion of the corporate tax base, there is a stronger sense that the

91 Bansal, P., Jiang, G. F. and Jung, J. C. (2015), 'Managing Responsibly in Tough Economic Times: Strategic and Tactical CSR During the 2008-2009 Global Recession', Long Range Planning, 48(2), pp. 69-79. 
private sector must respond in other ways to be socially responsible in an age of global environmental and human challenges. ${ }^{92}$ Business has also needed to respond and realign itself to a more ethical consumer mindset during the pandemic, which is likely to increase demand for more responsible products and business practices. ${ }^{93}$

COVID-19 has been a catalyst for further movement towards more socially responsible capitalism. In June 2020, more than 200 leading UK businesses signed a letter calling on the Government to deliver a COVID-19 recovery plan that aligns with 'wider social, environmental and climate goals'. ${ }^{94}$ Corporations, both in the UK and elsewhere, have appeared more comfortable working alongside governments and other actors to innovate and responding to the societal effects of the crisis, and the pandemic has acted as a concrete example of how they can show practical commitment to internationally recognised frameworks such as the United Nations Sustainable Development Goals. ${ }^{95}$ Other large employers, such as universities and colleges, are also expanding their sense of civic duty and social responsibility, and will play an ever more important and complex role in supporting sustainable development.

Despite the greater willingness on the part of business to be more socially responsible, the UK faces major economic upheaval, with rising unemployment and income inequalities. The current benefits system is likely to struggle to respond to the type of unemployment and income inequalities we will face, as they are driven largely by macroeconomic conditions, and the use of benefit conditions to incentivise job seeking will be ineffective in a labour market where 'even an intense and effective job search may be much less likely to result in finding a job'. ${ }^{96}$ There is also evidence of public opinion shifting towards wider support for increased social security spending to tackle unemployment, including support for universal basic income. ${ }^{97}$ As a result, government may need to think more innovatively about how it supports the unemployed and those on low incomes, moving away from conditional benefits and looking to ways in which all groups can be empowered to play a socially valuable role in the recovery. This must also take into account ways in which social security can better withstand major economic and social shocks, avoiding the need to create new ad hoc support schemes at short notice.

Volunteering, whether informally through mutual aid groups or formally through nationally constituted organisations, has been at the heart of community-based support and solidarity throughout the pandemic. Local volunteers have collected prescriptions, helped with groceries, distributed food parcels and checked in on vulnerable, isolated people. Perhaps most importantly, they have shared vital local knowledge and information about who is most in need of support and the kind of support that is needed. If local volunteering and community support networks can be brought together and supported as part of a national effort during the recovery, the social engagement can rebuild trust and cohesion, improve health and wellbeing, and help tackle inequalities, making society stronger and more resilient overall. ${ }^{98}$

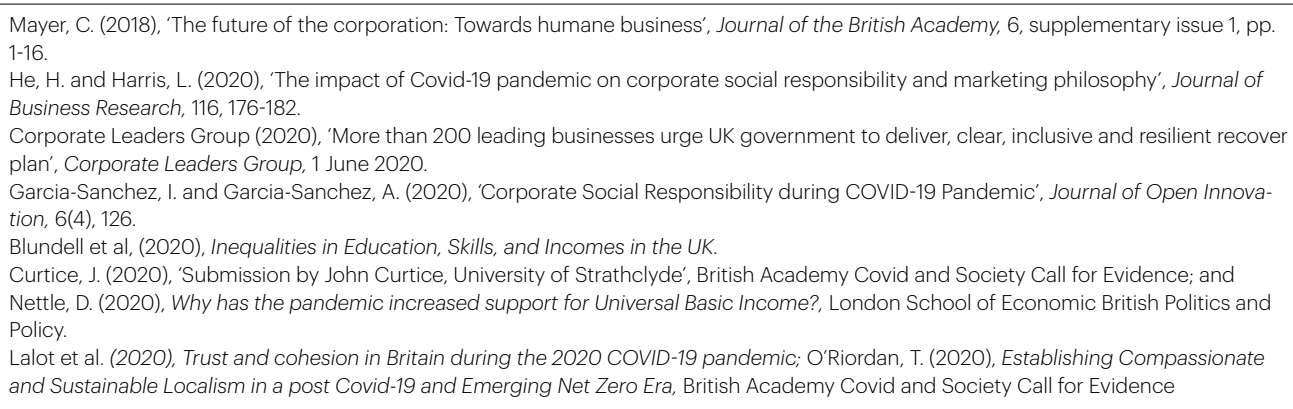




\subsubsection{Policy opportunities}

- Consider creating a national recovery participation scheme focused on harnessing the skills and time of the population for the recovery. This should be a major volunteering initiative, facilitated by central and local governments and supported by a wide range of actors, including businesses, social enterprises, civil society organisations, charities, faith and belief groups, educational institutions and media.

- Explore ways to lessen the 'conditionality' of out-of-work benefits and offer additional incentives for the unemployed to engage in community-led activities and retraining, while enabling those out of work to keep vital benefits while engaging in these mutually beneficial activities.

- Find ways to further incentivise commitment to principles for purposeful business ${ }^{99}$ in the private sector to drive recovery-oriented innovation and encourage even stronger and more targeted contribution to social and environmental solutions.

- Review the implications of the workforce divide between those who can work remotely and those who cannot and the new inequalities that could emerge between these two groups. The review should aim to make recommendations on how to ensure changes in the labour market and ways of working do not create new inequalities or accentuate existing ones, and instead create mutual benefits for individuals, businesses and the wider economy and society.

- Consider options which provide a better settlement for those in precarious work, on zero-hour contracts and the underemployed, who have continued and will continue to work under difficult and unprotected circumstances. 


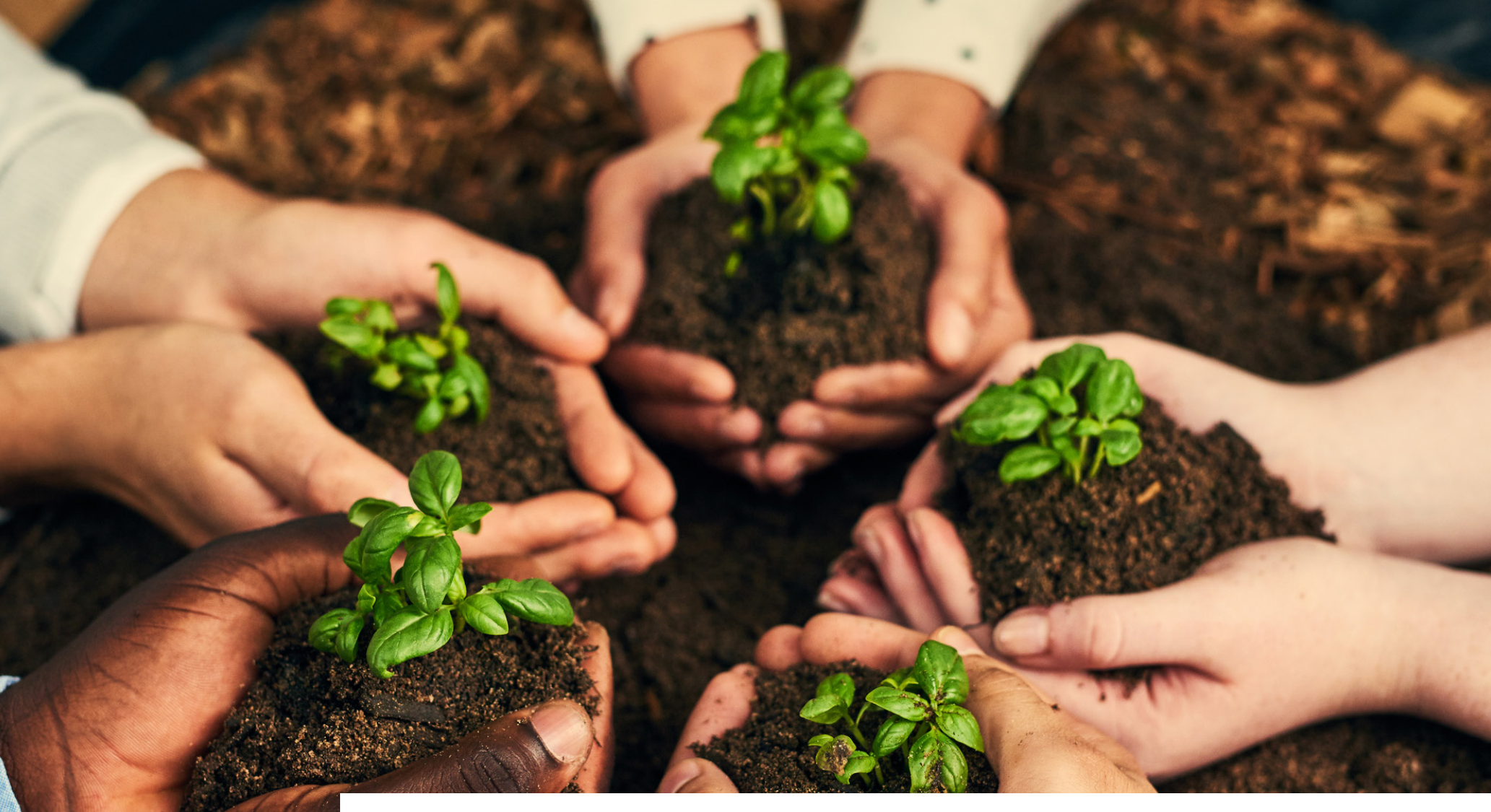

\subsection{The policy environment in 2030}

We believe that the seven strategic goals detailed in the previous chapter can be taken up by decision-makers at all levels, in every part of the country, to respond to the areas of long-term societal impact of COVID-19 and help build a thriving society in the UK by the end of the decade.

However, the actions of decision-makers are taken within a wider policy environment with its own cultures, norms and relationships, as well as complex structures and processes. In this final section, we bring the strategic goals together and underpin them by thinking about the underlying policy environment that would allow different actors to work effectively towards these goals and ensure a strong and thriving social recovery.

Our policy environment needs work. By considering what outcomes we might like to see on the horizon, we can plan and start the journey towards it. Here, we set out central principles of a supportive policy environment that we have identified from our evidence reviews and analyses. A successful recovery by 2030 requires the policy environment to be CLEAR: Communicative, Learning, Engaging, Adaptive and Relational. These principles work collectively to support the delivery of the strategic goals identified in Chapter 3. We present this relationship in the diagram on the following page. 


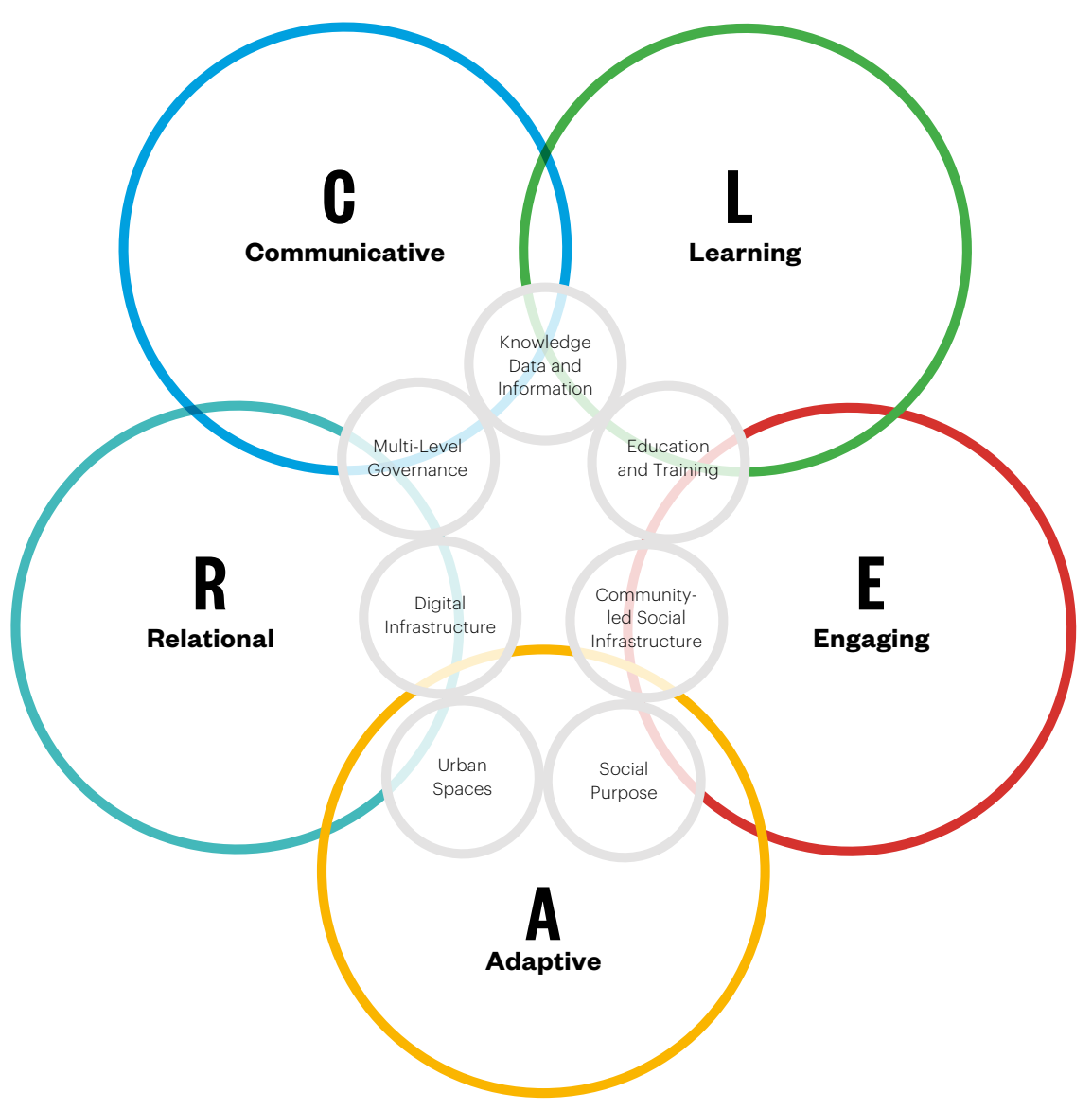

\subsection{CLEAR principles of the policy environment}

\subsubsection{Communicative}

The public receives clear and consistent information with a high level of trust in its veracity, and both public and private actors are working together to combat the spread of misinformation successfully. Different government departments and agencies are communicating effectively and sharing information and data in the coordination of policy.

\subsubsection{Learning}

There is a strong culture of mobilising information and evidence to inform policy embedded within all levels of government. The nexuses between the communities of research, policy and practice have been considerably strengthened, with more frequent and meaningful opportunities for creative interactions, breaking down cultural and practical barriers and political resistance. Decisions are made with hindsight of past successes and failures, and a widely held knowledge of history, with effective transfer of knowledge of what works, and the lessons learned from what does not. Scientific and technological innovation is developed within a strong interdisciplinary understanding of societal needs and the social determinants of successful deployment. 


\subsubsection{Engaging}

Citizens and non-state actors are engaging meaningfully and constructively in a fair and healthy democratic system. There is transparency and trust in the decisionmaking processes of government at all levels, with clear levers for parliamentary and public scrutiny. Local communities are playing a key role in decisions that affect them, and the voices of previously underrepresented groups - such as children and young people, ethnic minorities, disabled people and those who are unemployed or in precarious work - are given fair hearing.

\subsubsection{Adaptive}

The UK in 2030 will have the right infrastructure, information and capacity to prepare effectively for threats on the horizon. Different actors will work collaboratively - and with a shared understanding of the issues that society faces with researchers, business leaders, policymakers, and civil society figures, adopting problem-driven approaches to build local resilience and readiness. Adaptive strategies react innovatively to uncertainty in a multi-level system and allow more effective planning of smart infrastructure and service provision.

\subsubsection{Relational}

Decision-makers have fully embraced the art of joining up strategies across different departments and at different levels of scale. Policy is developed and implemented with awareness of knowledge and practice in different local and regional contexts, and the connections between different policy issues are carefully considered as part of a coordinated approach. There are strong and supportive working relationships between different levels of government.

\subsection{How we can shape the COVID decade}

We noted at the beginning of this report that the review built on work the British Academy had already been doing as part of a wide-ranging consultation with a large number of leading scholars and practitioners to understand how we can shape a positive post-pandemic future..$^{100}$ One of the most powerful ideas emerging from that effort, and this one, is that pandemics are as much social and economic events as they are health and medical ones, and that the temporal, scalar and place-based dimensions of our response play a significant role in understanding how interventions could interact with the observed effects of COVID-19 on society and alter their long-term impact. Relationships, lives, livelihoods and the interconnections between them, will all play a role. To grapple with all this effectively, we will need insight from across stakeholders and disciplinary communities, across both science and medicine and the humanities and social sciences, to assess the various paths forward.

This review has set out a vision for the end of the decade based on what our evidence tells us about our direction of travel. We built on our knowledge of the present crisis and by reflecting on what we know from the past. Crises provoke societal and cultural changes in parallel with policy responses, and in response to past crises society often 
found ways to rebuild and gather new strength. ${ }^{101}$ Responding to these changes now and ahead requires analysis of the interconnected evidence and the context which has led to them. To move forward, there should be a shared vision and framework and a set of principles for action which can adapt to the inevitable uncertainties ahead. The pandemic has shown us that our 21st-century society remains vulnerable, albeit in new and different ways from some societies of the past. Our ability to adapt and move forward depends on our making best use of the evidence and expertise available; we hope that this review illustrates the value of doing so. 


\section{References}

Abrams, D. (2010), Processes of prejudice: Theory, evidence and intervention, Equalities and Human Rights Commission, Research Report 56, Centre for the Study of Group Processes, University of Kent.

Abrams, D., Hand, D.J., Heath, A., Nazroo, J., Richards, L., Karlsen, S., Mills, M., Roberts, C. and the Centre for Homelessness Impact (2020), What Factors make a community more vulnerable to COVID-19? A summary of a British Academy Workshop, The British Academy.

Abrams, D., Lalot, F., Broadwood, J. and Davis Hayon, K. (2021), Community, Connection and Cohesion During COVID-19: Beyond Us and Them Report, Nuffield Foundation.

Abrams, D. and Vasiljevic, M.D. (2014), 'How does macroeconomic change affect social identity (and vice versa)?: Insights from the European context', Analysis of Social Issues and Public Policy, 14(1), pp. 311-338.

Andrew, A., Cattan, S., Costa-Dias, M., Farquharson, C., Kraftman, L., Krutikova, S., Phimister, A. and Sevilla, A. (2020), Family Time Use and Home Learning During the Covid-19 Lockdown, The Institute for Fiscal Studies.

ARUP (2020), COVID-19 Mobility Insights: Rebuilding Resilient Cities.

Bansal, P., Jiang, G. F. and Jung, J. C. (2015), 'Managing Responsibly in Tough Economic Times: Strategic and Tactical CSR During the 2008-2009 Global Recession', Long Range Planning, 48(2), pp. 69-79.

Berridge, V. and Mold, A. (2021), Personal communication and submission to The British Academy Covid and Society Review.

Benzeval, M., Burton J., Crossley, T. F., Fisher, P., Jäckle, A., Low, H. and Read, B. (2020), 'The Idiosyncratic Impact of an Aggregate Shock: The Distributional Consequences of COVID-19', Understanding Society Working Paper Series, Paper No. 09.

Birn, A. (2020), 'Perspectivizing pandemics: (how) do epidemic histories criss-cross contexts?', Journal of Global History, 15(3), 336-349.

Bloomfield, R. (2020), 'London Development to Test Demand for 15-Minute Cities After Covid-19', Wall Street Journal, 22 December 2020.

Blundell, R., Cribb, J., McNally, S., Warwick, R. and Xu, X. (2020), Inequalities in Education, Skills, and Incomes in the UK: The Implications of the COVID-19 Pandemic.

Brent Cross Town, (2021), A Park Town for Future London, [accessed 10 March 2021].

The British Academy, (2019), Principles for Purposeful Business: How to deliver the framework for the Future of the Corporation.

The British Academy, (2020), Qualified for the Future: quantifying demand for arts, humanities and social science skills.

Buck, D. (2020), The English local government public health reforms: An independent assessment, The King's Fund.

Burchell, J. (2020), 'Submission by Jon Burchell', University of Sheffield, British Academy Covid and Society Call for Evidence.

Carozzi, F., Provenzano, S. and Roth, S. (2020), 'Urban Density and Covid-19', London School of Economics and Political Science Centre for Economic Performance, Discussion Paper No. 1711. 
Cheung, A. (2020), 'Barnett Formula', Institute for Government, [accessed 10 March 2021].

Connolly, C., Keil, R. and Harris Ali, S. (2020), 'Extended urbanisation and the spatialities of infectious disease: Demographic change, infrastructure and governance', Urban Studies, 58(2), pp. 245-263.

Corporate Leaders Group (2020), 'More than 200 leading businesses urge UK government to deliver, clear, inclusive and resilient recover plan', Corporate Leaders Group, 1 June 2020.

Coyle, D. and Lu, S. (2020), 'Trust and Productivity Growth - An Empirical Analysis', Bennett Institute Working Paper.

Curtice, J. (2020), 'Submission by John Curtice, University of Strathclyde', British Academy Covid and Society Call for Evidence.

Davison, C., Davey Smith, G. and Frankel, S. (1991), 'Lay Epidemiology and the Prevention Paradox: The Implications of Coronary Candidacy for Health Education', Sociology of Health \& IIIness, 13(1), pp. 1-19.

Dowd, J.B., Ding, X., Akimova, E.T. and Mills, M. (2020), Health and inequality: The implications of the COVID-19 pandemic, Leverhulme Centre for Demographic Science, University of Oxford.

Educational Endowment Foundation (2020), 'Submission to the British Academy Covid and Society Call for Evidence'.

Feinstein, F. (2003), 'Inequality in the Early Cognitive Development of British Children in the 1970 Cohort', Economica, 70, pp. 73-97.

Felici, M. (April 2020), 'Social Capital and the response to Covid-19', Bennett Institute for Public Policy, 21 April 2020 .

Garcia-Sanchez, I. and Garcia-Sanchez, A. (2020), 'Corporate Social Responsibility during COVID-19 Pandemic', Journal of Open Innovation, 6(4), 126.

Goodair, B. Kenny, M. and Marteau T.M. (2020), Townscapes: England's Health Inequalities, Bennett Institute for Public Policy.

Grecksch, K. (2020), 'Rapid review of evidence on Covid-19 and sustainability for the British Academy'.

Hansen, K. and Hawkes, D. (2009), 'Early Childcare and Child Development', Journal of Social Policy, 38, pp. 211-39.

He, H. and Harris, L. (2020), 'The impact of Covid-19 pandemic on corporate social responsibility and marketing philosophy', Journal of Business Research, 116, 176-182.

Heckman, J. (2004), 'Lessons from the Technology of Skill Formation', Annals of the New York Academy of Sciences, 1038(1), pp. 179-200.

Jerrim, J. and Macmillan, L. (2015), 'Income inequality, intergenerational mobility, and the Gatsby curve: Is education the key?', Social Forces, 94(2), pp. 505-533.

Johnston, A. (2021), Lessons Learned: Where women stand at the start of 2021: The economic and health impacts of Covid-19, Women's Budget Group.

Kaptan, G. (2020), Capitalising on COVID-19 as a trigger for positive change in food waste behaviour, British Academy Covid and Society Call for Evidence.

Kenny, M \& J. Sheldon, (2020), 'How COVID-19 is exposing unresolved issues about how England is governed', British Academy Blog, 6 July 2020.

Lalot, F., Davies, B. and Abrams, D. (2020), Trust and cohesion in Britain during the 2020 COVID-19 pandemic across place, scale and time. Report for the British Academy, November 2020, Centre for the Study of Group Processes, School of Psychology, University of Kent. 
Leyser, O. and Richardson, G. (2017), Data management and use: governance in the 21st century, The British Academy and The Royal Society.

London Assembly Housing Committee, (2020) 'Half of Londoners wanting to move home want out of London'.

Mayer, C. (2018), 'The future of the corporation: Towards humane business', Journal of the British Academy, 6 , supplementary issue 1, pp. 1-16.

McEwan, N. Kenny, M., Sheldon, J. and Brown Swan, C. (2020), 'Intergovernmental Relations in the UK: Time for a Radical Overhaul?', The Political Quarterly, 91(3), pp. 632-640.

Mills, M. (2020), COVID-19 vaccine deployment: Behaviour, ethics, misinformation and policy strategies, The Royal Society and The British Academy.

Mold, A., Berridge, V. and Taylor, S. (2020), British Academy Commission: COVID and Society. The History of Public Health Crises, Governance and Trust, Centre for History in Public Health, London School of Hygiene \& Tropical Medicine, The British Academy Covid and Society Review.

Morgan Jones, M., Abrams, D. and Lahiri, A. (2020), 'Shape the Future: how the social sciences, arts and the humanities can shape a positive, post-pandemic future', Journal of the British Academy, 8, pp. 167-266.

Morrison, E., Fransman, J. and Bulutoglu, K. (November 2020), The social implications of Covid-19 on communities, The Institute of Community Studies, The British Academy Covid and Society Review.

Nettle, D. (2020), Why has the pandemic increased support for Universal Basic Income?, London School of Economic British Politics and Policy.

Nielsen, R.K., Fletcher, R., Kalogeropoulos, A. and Simon, F. (October 2020), Communications in the coronavirus crisis: lessons for the second wave, Reuters Institute for the Study of Journalism.

Nielsen, R. K., Kalogeropoulos, A. and Fletcher, R. (2020), 'Social media very widely used, use for news and information about COVID-19 declining', Reuters Institute for the Study of Journalism.

OECD (2020), Cities policy responses.

OECD (2020), The territorial impact of COVID-19: Managing the crisis across levels of government, OECD Policy Responses to Coronavirus (COVID-19).

Office for National Statistics (May 2020), One in eight British households has no garden [accessed 10 March 2021].

Onward (2020), Repairing our social fabric, Onward.

O'Riordan, T. (2020), Establishing Compassionate and Sustainable Localism in a post Covid-19 and Emerging Net Zero Era, British Academy Covid and Society Call for Evidence.

Phillips, D. (2020), Lessons and issues for sub-national government finances post-COVID, Institute for Fiscal Studies.

PwC (January 2021), UK Economic Outlook.

Roe, B. E., Bender, K. and Qi, D. (2020), 'The Impact of COVID-19 on Consumer Food Waste', Applied Economic Perspectives and Policy, Special Collection on COVID-19, 43(1), pp. 401-411.

Roelich, K. (2020), Submission from the Sustainability Research Institute, University of Leeds, British Academy Covid and Society Call for Evidence.

Sharifi, A. and Khavarian-Garmsir A.R. (2020), 'The COVID-19 pandemic: Impacts on cities and major lessons for urban planning, design, and management', Science of the Total Environment, 749.142391. 
Shoari, N., Ezzati, M., Baumgartner, J., Malacarne, D. and Fecht, D. (2020), 'Accessibility and allocation of public parks and gardens in England and Wales: A COVID-19 social distancing perspective', PLOS ONE, 15(10).

Smith, B., Hopkins, C., Whitcroft, K., Kelly, C., Burgess Watson, D.L. and Deary, V. (2020), Covid and Society: Accessing Healthcare before, during and after the pandemic, School of Advanced Study, University of London.

Tang, C. (2020), 'British Academy Covid and Society Evidence Call', 21 December 2020.

UK2070 Commission (2020), Make No Little Plans: Final Report of the UK2070 Commission, UK2070 Enquiry: An Inquiry into Regional Inequalities Towards a Framework for Action.

Warrington, J. (2020), 'Full-Fibre broadband failings 'disproportionately' hit small business', CityAM, 28 October 2020.

WRAP (2020), Food waste and Covid-19 survey 3: Life in flux.

\section{About the Academy}

The British Academy is an independent, self-governing corporation, composed of almost 1,000 UK Fellows and 300 overseas Fellows elected in recognition of their distinction as scholars and researchers. Its objectives, powers and framework of governance are set out in the Charter and its supporting Bye-Laws, as approved by the Privy Council. The Academy receives public funding from the Science and Research budget allocated by a grant from the Department for Business, Energy and Industrial Strategy (BEIS). It also receives support from private sources and draws on its own funds. 


\title{
Acknowledgements
}

\begin{abstract}
Staff
Staff from across the British Academy's Policy Directorate have made substantial contributions to the Covid \& Society programme and the policy research and synthesis presented in these pages. Their dedication and expertise in policy analysis has made this report and its production possible, and all of the following should be recognised as significant authors of the material in these pages:
\end{abstract}

\section{Anna Bradshaw \\ Senior Policy Adviser}

Sarah Cowan

Deputy Head of Policy (HE \& Skills)

\section{Dr Alex Mankoo}

External Policy Consultant

\author{
Dr Molly Morgan Jones \\ Director of Policy

\section{Dr Joanna Thornborough} \\ Policy Adviser \\ Dr Adam Wright \\ Head of Public Policy
}

We are also appreciative of the support of Alexandra Paz and Imogen Steinberg, Policy Assistants, who have provided help and assistance throughout the programme.

\section{Academic Lead}

Professor Dominic Abrams FBA has provided invaluable leadership and support for the programme, working closely with the Policy Directorate, the Advisory Groups, and the wider community we convened throughout. Without this leadership, the programme would not have been possible.

\section{Advisory Groups}

The conclusions of this report have been guided by the advice and insights of the Steering Group and the External Reference Group. Members acted in an individual, not representative capacity and the views expressed in this report are not necessarily those of each member.

\section{Steering Group members}

Lead Fellow: Professor Dominic Abrams FBA, Professor of Social Psychology and Director of the Centre for the Study of Group Processes, University of Kent

Fellows:

Professor Genevra Richardson FBA

(British Academy V-P Public Policy), Emeritus Professor, King's College London

\section{Professor Aditi Lahiri FBA}

(British Academy V-P Humanities), Professor of Linguistics, University of Oxford

\section{Professor Patricia Clavin FBA}

Zeitlyn Fellow and Tutor in History, Professor of International History, University of Oxford

\section{Professor Peter Taylor-Gooby FBA Research Professor of Social Policy, University of Kent}

Professor Melinda Mills FBA

Nuffield Professor of Sociology, Director Leverhulme Centre for Demographic Science 


\section{External Reference Group members}

Professor Dame Theresa

Marteau FMedSci

Director of Behaviour and Health

Research Unit, University of Cambridge

\section{Tim Chapman FRAEng}

Director, Infrastructure Design, Arup

Professor Peter Smith FRS

Professor of Soils and Global change, University of Aberdeen

Dr João Rangel de Almeida

Portfolio Development Manager,

The Wellcome Trust

\section{Tim Gardam}

Chief Executive, Nuffield Foundation

Professor Alison Park

Interim Chief Executive, ESRC

Professor Edward Harcourt

Director of Research, AHRC
John Pullinger

Former National Statistician

\section{Vidhya Alakeson}

CEO, Power to Change

\section{Dr Claire Craig}

The Provost, The Queen's College,

University of Oxford

\section{Ray Shostak}

Member of British Academy Public Policy Committee, Former Head of the Prime Minister's Delivery Unit, Director General, Performance Management and member of the Board of Her Majesty's Treasury from 2007-2011

\section{Stephen Aldridge}

Chief Analyst/ Chief Economist and Director of Analysis and Data Directorate, MHCLG 
The British Academy is the UK's national academy for the humanities and social sciences. We mobilise these disciplines to understand the world and shape a brighter future.

From artificial intelligence to climate change, from building prosperity to improving well-being - today's complex challenges can only be resolved by deepening our insight into people, cultures and societies.

We invest in researchers and projects across the UK and overseas, engage the public with fresh thinking and debates, and bring together scholars, government, business and civil society to influence policy for the benefit of everyone.
The British Academy 10-11 Carlton House Terrace London SW1Y $5 \mathrm{AH}$

Registered charity no. 233176

thebritishacademy.ac.uk

Twitter: @BritishAcademy

Facebook: TheBritishAcademy

Published March 2021

(c) The British Academy. This is an open access publication licensed under a Creative Commons Attribution-NonCommercial-NoDerivs 4.0 Unported License

ISBN 978-0-85672-659-0

To cite this report:

British Academy (2021), Shaping the COVID decade: Addressing the long-term societal impacts of COVID-19, The British Academy, London

DOI doi.org/10.5871/ doi.org/10.5871/ bac19stf/9780856726590.001

Design by Only

\section{The British Academy 31 COVID-19 and Society}

